\title{
Physical and Structural Characterization of Monocrystalline Cu-13.7\% Al-4.2\% Ni Alloy Submitted to Thermo-Cyclical Treatments under Applied Loads
}

\author{
Lioudmila A. Matlakhova ${ }^{1, *}$, Elaine C. Pereira ${ }^{1}$, Serguey A. Pulnev ${ }^{2}$, Carlos Y. Shigue ${ }^{3}$ and \\ Natalia A. Palii ${ }^{4}$ \\ 1 Advanced Materials Laboratory, Science and Technology Center, Darcy Ribeiro State University of Northern \\ Rio de Janeiro, Campos dos Goytacazes 28013-620, Brazil; elainecp@pq.uenf.br \\ 2 Division of Solid State Physics, Ioffe Institute, St. Petersburg 194021, Russia; pulnev@mail.ru \\ 3 Lorena School of Engineering, University of São Paulo, São Paulo 05508060, Brazil; cyshigue@usp.br \\ 4 Laboratory of Physical Chemistry of Amorphous and Nanocrystalline Alloys, A.A. Baikov Institute of \\ Metallurgy and Materials Science, Russian Academy of Sciences, Moscow 119334, Russia; \\ palii.natalia59@gmail.com \\ * Correspondence: lioudmila@uenf.br; Tel.: +55-229-8811-9042
}

Received: 19 December 2019; Accepted: 25 January 2020; Published: 4 February 2020

\begin{abstract}
Monocrystalline alloy with a nominal composition of $\mathrm{Cu}-13.7 \% \mathrm{Al}-4.2 \% \mathrm{Ni}$ (wt.\%) that shows reversible martensitic transformations (RMTs) was studied. The alloy, manufactured by the "Memory Crystals Group" in Russia, was subjected to thermo-cyclical treatment (TCT) under tension within a range that included critical RMT temperatures. A special device was developed to perform TCTs (up to 500 cycles) and three different loads were applied: 0.11, 0.26, and 0.53 MPa. X-ray diffraction analysis, optical microscopy, differential calorimetry, and Vickers microhardness were involved in the alloy's characterization. Under TCTs, the alloy displayed complex structural transformation, revealing the sequence of RMT, $\beta_{1} \leftrightarrow \mathrm{R} \leftrightarrow \beta^{\prime}{ }_{1}+\gamma^{\prime}{ }_{1}$; the involved phases were coherently precipitated but very sensitive to the experimental conditions. It was found that during TCTs (from 300 cycles) performed under optimum load $(0.26 \mathrm{MPa})$, the processes of martensite reorientation, hardening, and stabilization of the structure were the most intensive thus leading to a reduction of RMT critical intervals and increased microhardness.
\end{abstract}

Keywords: $\mathrm{Cu}-\mathrm{Al}-\mathrm{Ni}$ monocrystalline alloy; reversible martensitic transformations; thermo-cyclic treatment under load; physical characterization and structural characterization

\section{Introduction}

Metal alloys exhibiting the shape memory effect (SME) have specific properties due to the fact of reversible martensitic transformations (RMTs) [1-3]. Widely used in industrial and medical applications, TiNi-based alloys have superb SME characteristics [3-6], but owing to their high cost, other shape memory alloys (SMAs) are under consideration. Copper-based SMAs cost less; moreover, they have high transformation temperatures, superior thermal and electrical conductivity, and large recoverable strain [7-9].

Monocrystalline $\mathrm{Cu}-\mathrm{Al}-\mathrm{Ni}\left(\mathrm{Cu}_{3} \mathrm{Al}\right.$-based) alloys have received special attention, because they display high SME parameters along with good thermoelastic properties, formability, and plasticity without embrittlement at high temperatures [7-13]. Such SMAs are based on the $\mathrm{Cu}_{3} \mathrm{Al}$ intermetallic compound; they have different structures, depending on the composition, temperature, heat treatment, 
and deformation. At elevated temperatures, the $\mathrm{Cu}_{3} \mathrm{Al}$-based alloys have a structure of a $\beta$-phase, a body-centered cubic (BCC) phase, but below $565^{\circ} \mathrm{C}$, it undergoes the ordering to form the metastable $\beta_{1}$ phase, an ordered cubic structure of the $\mathrm{DO}_{3}$ type [14,15]. With subsequent cooling and depending on the aluminum content, the ordered $\beta_{1}$ phase, in turn, can transform into either martensite $\gamma^{\prime}{ }_{1}$, the ordered phase of $\mathrm{Cu}_{3}$ Ti type, or martensite $\beta^{\prime}{ }_{1}$, the ordered phase of $\mathrm{Cu}_{3} \mathrm{Al}$ type $[1,3,15]$. Aside from the aforementioned phases, the diffractograms of monocrystalline $\mathrm{Cu}-\mathrm{Al}-\mathrm{Ni}$ alloys may display additional peaks that can be attributed to the rhombohedral ordered $\mathrm{Al}_{7} \mathrm{Cu}_{4} \mathrm{Ni}$ phase (JCPDS: 28-0016) with the space-group R-3m of the trigonal crystal system [16,17]. In our previous work [12,18,19], it was shown that the microstructures of $\mathrm{Cu}-\mathrm{Al}-\mathrm{Ni}$ alloys revealed the presence of the rhombohedral ordered $\mathrm{Al}_{7} \mathrm{Cu}_{4} \mathrm{Ni}$ phase, so the additional peaks in diffractograms would be due to (1) the ordering of the $\mathrm{Ni}$ atoms incorporated into the crystalline lattice of alloy and/or (2) the development of a transitional crystal lattice state during RMT, $\beta_{1} \leftrightarrow \gamma^{\prime}{ }_{1}$ [15-19]. The $\mathrm{Al}_{7} \mathrm{Cu}_{4} \mathrm{Ni}$ phase is called the R-phase in the present study as in our previous works [18-22].

Multiple heating/cooling cycles within a temperature range, which includes critical RMT temperatures, are required to perform a repetitive SME regime for investigated alloys. The restrictions in the practical application of SMAs are the possible undesirable changes in the SMAs' structure and performance after multiple thermal cycles. As is well known, thermos-cyclical treatments (TCTs) promote changes in the structure and phase composition of the alloy thus modifying its physical and mechanical properties [3,7-11]. In fact, each thermal cycle may produce additional imperfections, resulting in changes in RMT behavior, namely, the change in RMT critical temperatures $[7,8,11]$.

Reversible martensitic transformations can develop under applied loads as well as thermal stresses in alloys that are used in force elements of several actuators. The applied loads give rise to tensions, deformations, and transformations of metastable phases (induced transformations) thus changing the structure and properties of the material in a complex way [4,7-13].

This work was conducted as the continuation of our work examining the effect of cyclic tests on monocrystalline alloys of the $\mathrm{Cu}-\mathrm{Al}-\mathrm{Ni}$ system on the structure, critical temperatures, and hysteresis of reversible martensitic transformations, involving multiple cycles of heating above $A_{f}$ and cooling below $\mathrm{M}_{\mathrm{f}}$; we changed the test conditions and the composition of the studied alloys. So, in Reference [12], monocrystalline $\mathrm{Cu}-13.5 \mathrm{Al}-4 \mathrm{Ni}$ alloys were subjected to 100,200 , and 300 thermal cycles (TC) without load. In Reference [13], we studied two monocrystalline alloys: $\mathrm{Cu}-13,5 \mathrm{Al}-4 \mathrm{Ni}$ and $\mathrm{Cu}-13,7 \mathrm{Al}-4,2 \mathrm{Ni}$ in the initial state and after 1, 100, and 200 thermal cycles (TCs) without load. In Reference [18], monocrystalline $\mathrm{Cu}-13.5 \mathrm{Al}-4 \mathrm{Ni}$ alloy was subjected to thermal cycling treatments conducted for 100 , 200 , and 300 cycles free of load and under a static load of $0.5 \mathrm{~kg}$, corresponding to a compressive stress of 0.28 MPa. This stress was a fraction of the alloy's "pseudo-yield" stress, determined as 60-65 $\mathrm{MPa}$. In other tests, thermal cycling treatment was performed under different loads of 0.2 and $0.5 \mathrm{~kg}$ involving 300 cycles. In Reference [19], the same alloy was subjected to 300 thermal cycling treatment in a load-free regime and under three different applied load of $0.1,0.2$, and $0.5 \mathrm{~kg}$, corresponding to $0.056,0.112$, and $0.280 \mathrm{MPa}$, respectively; and in Reference [20], this alloy passed through three distinct thermal cycling treatments involving 100, 200, and 300 cycles under one static load of $0.5 \mathrm{~kg}$ $(0.280 \mathrm{MPa})$. These tests revealed that the monocrystalline $\mathrm{Cu}-13.5 \mathrm{wt} . \% \mathrm{Al}-4.0 \mathrm{wt} . \% \mathrm{Ni}$ alloy suffered reversible martensitic transformation, $\gamma^{\prime}{ }_{1} \leftrightarrow \beta_{1}$ associated with a thermal hysteresis of about $20^{\circ} \mathrm{C}$ when subjected to thermal cycling treatments. The phase transformation enthalpies of endothermic (direct) and exothermic (reverse) processes in the initial state and in a first of load-free thermal cycles were approximately 6.8-7.4 J/g. The thermal hysteresis of the RTM promotes changes in the number of phases associated with the RMT. These changes depend on the way the treatment ends, either by heating or by cooling. After 300 TCs without load, displacement of the critical temperatures $M_{0}, M_{f}$, $A_{o}, A_{s}$ as well as the peak temperatures $A_{e}$ and $M_{e}$ is observed towards values up to $10{ }^{\circ} \mathrm{C}$ lower, while $\mathrm{M}_{\mathrm{s}}$ increases by more than $10^{\circ} \mathrm{C}$. This contributes to enlarging the temperature interval of the RMT occurrence. By contrast, no change occurred in the thermal hysteresis. After a load-free $300 \mathrm{TCs}$, if the end occurs by heating above $A_{f}$, a larger amount of $\beta_{1}$ is transformed. If the end 
occurs by cooling below $\mathrm{M}_{\mathrm{f}}$, an intermediate structure, the R-phase, related to the $\gamma^{\prime}{ }_{1} \leftrightarrow \beta_{1}$ is found. This is apparently a consequence of accumulated structural defects that retard the RMT and tend to stabilize the intermediate stage. The alloy submitted to TCs under a load of $0.5 \mathrm{~kg}$ revealed a tendency towards a decrease in the critical intervals for both direct and reverse martensite transformation with an increasing number of cycles. This tendency is accentuated for treatments up to 300 cycles in which critical temperature intervals of RMTs smaller than $10^{\circ} \mathrm{C}$ were recorded. The hysteresis of the RMT also decreased. This can be attributed to a higher participation of the R-phase, particularly above 200 cycles, either alone or coherent with $\gamma^{\prime}{ }_{1}$ (direct on cooling) and $\beta_{1}$ (reverse on heating). It is also suggested that the applied load contributes to the shape deformation observed in blocks of martensite variants. Despite complex structural transformations, the monocrystalline Cu-13.5wt.\% Al-4.0wt.\% Ni alloy showed good resistance to irreversible changes during applied tests.

In a more recent work [21], we paid attention to the behavior of a monocrystalline $\mathrm{Cu}-13.7 \mathrm{Al}-4.2 \mathrm{Ni}$ alloy subjected to thermal cycling treatment induced for 1, 100, 200, 300, 400, and 500 cycles without applied load, i.e., stress free.

In the current work, which revisits and expands our research, monocrystalline $\mathrm{Cu}-13.7 \% \mathrm{Al}-4.2 \%$ $\mathrm{Ni}$ alloy was subjected to up to 500 cycles under three constant loads within a critical RMT temperatures range along with the physical and structural characterization of the alloy during applied TCTs.

\section{Materials and Methods}

The basic material investigated was a high purity monocrystalline Cu-13.7wt.\% Al-4.2wt.\% Ni alloy, obtained as a cylindrical bar ( $4 \mathrm{~mm}$ in diameter) from the Memory Crystals Group of the Technical University of Saint Petersburg, Russia [23]. Specimens approximately $4 \mathrm{~mm}$ in thickness were sectioned out perpendicular to the bar axis by means of a Minitom cutter (Struers A/S Pederstrupvej, Denmark). For microstructure characterization, the specimens were polished to an acceptable mirror finish using $0.1 \mu \mathrm{m}$ alumina paste. No chemical etching was used, since the surface relief of transformation was enough to reveal the phases.

Specimens were submitted to $1,100,200,300,400$, and 500 thermal cycles of heating up to $90{ }^{\circ} \mathrm{C}$ (above $\mathrm{A}_{\mathrm{f}}$-in the initial state) followed by cooling to $0{ }^{\circ} \mathrm{C}$ (below $\mathrm{M}_{\mathrm{f}}$-in the initial state). Each TCT was carried under a static load (TCTL). Three loads were applied: $0.14,0.35$, and $0.70 \mathrm{~kg}$, corresponding to the stress of $0.11,0.26$, and $0.53 \mathrm{MPa}$, respectively. The chosen loads were below the flow limit determined as $70 \mathrm{MPa}$ for this alloy $[18,21]$. The load was applied along with thermocycling using the special device developed for this purpose [18-22]. After TCTL, the structure of the alloy was analyzed by optical metallography and X-ray diffraction. Structural characterization was conducted at room temperature (RT) by finishing the treatment: (a) with a half cooling cycle to $0{ }^{\circ} \mathrm{C}$, then up to RT, and (b) with a half heating cycle to $90{ }^{\circ} \mathrm{C}$, then down to RT [12,18-22].

The phase structure of the alloy was determined at RT by X-ray diffraction (XRD) in both Shimadzu 7000 (SHIMADZU Corporation, Kyoto, Japan) and Seifert 65 diffractometers (Seifert GmbH, Ahrensburg, Germany) using $\mathrm{Cu}-\mathrm{K}_{\alpha}$ and $\mathrm{Co}-\mathrm{K}_{\alpha}$ radiations, respectively, for $2 \theta$ angles from $25^{\circ}$ to $75^{\circ}$ at scanning steps of $0.03^{\circ} / 3 \mathrm{~s}$.

The surface morphological relief induced by the phase transformation and the involved deformation-related defects were observed in a Neophot-32 microscope (Carl Zeiss AG, Oberkochen, Germany) with polarized light. The microhardness was measured with a Shimadzu HMV-2 Micro Vickers Hardness Tester (Shimadzu Corporation, Kyoto, Japan). The RMT critical temperatures and associated thermal effects after the TCTL were determined using a Q10 differential scanning calorimeter (TA Instrument Co. Ltd., New Castle, DE, USA). The thermal tests were conducted in the temperature range from $-50{ }^{\circ} \mathrm{C}$ to $+150{ }^{\circ} \mathrm{C}$ with a heating/cooling rate of $10^{\circ} \mathrm{C} / \mathrm{min}$ in an inert atmosphere. Cooling was carried out using an LNCA mode (liquid nitrogen cooling). After TCTL, the samples were submitted to two thermal cycles during the DSC runs. In the first cycle of the DSC analysis, the samples were cooled to $-50{ }^{\circ} \mathrm{C}$, then heated to $+150{ }^{\circ} \mathrm{C}$, and cooled and heated again within the indicated temperature range. To determine the thermal hysteresis value in our studies, we made use of the 
difference between the DSC peaks' critical temperatures upon heating and cooling $(\Delta T=\mathrm{Ap}-\mathrm{Mp})$, according to Morin and Trivero [11].

\section{Results}

\subsection{Analysis of the Monocrystalline Cu-13.7\% Al-4.2\% Ni Alloy in the Initial State}

Considering that the critical RMT temperatures of the studied alloy cover the ambient temperature (AT), special care was given to the structural analysis of the alloy before TCT. In other words, the structure of the alloy was examined in the as-received state and during the first load-free thermal cycle ending with the $1 / 2$ cooling cycle (AT $\rightarrow 0{ }^{\circ} \mathrm{C} \rightarrow \mathrm{AT}$ ), heating (AT $\rightarrow+90^{\circ} \mathrm{C} \rightarrow \mathrm{AT}$ ), and performing the XRD analysis at room temperature (Figure 1 ).

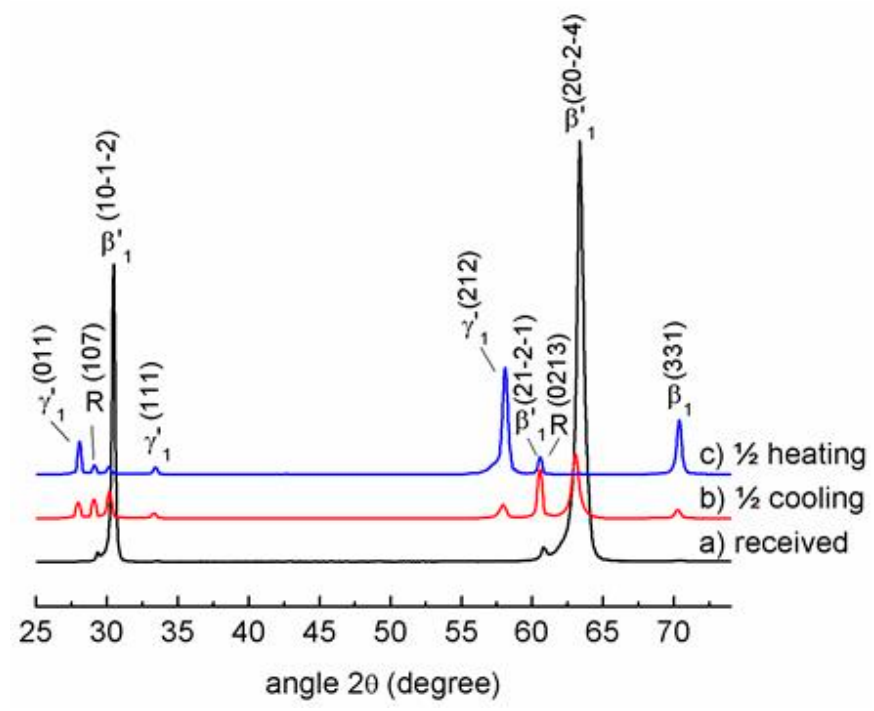

Figure 1. The XRD patterns of the alloy (a) in the as-received state, (b) after the $1 / 2$ cooling cycle, and (c) after the $1 / 2$ heating cycle.

The XRD pattern of the alloy in the as-received state in Figure 1a shows a significant amount of the $\beta^{\prime}{ }_{1}$ martensitic phase, determined by the intensive $\beta^{\prime}{ }_{1}$ and $\beta^{\prime}{ }_{1}$ peaks, traces of the R-phase, determined by the peak (107)R, and the other peak found for the R-phase coinciding with the peak belonging to the $\beta^{\prime}{ }_{1}$ phase and $\beta^{\prime}{ }_{1} \mid(0213) R$.

After the $1 / 2$ cooling cycle, in addition to the major $\beta^{\prime}{ }_{1}$ phase peaks, $\beta^{\prime}{ }_{1}$ and $\beta^{\prime}{ }_{1}$, the XRD pattern displays the martensitic $\gamma_{1}^{\prime}$ peaks, $(011) \gamma_{1}^{\prime}{ }_{1},(212) \gamma_{1}{ }_{1}$, and (111) $\gamma^{\prime}{ }_{1}$, the R-phase, peaks, (107)R, $\beta^{\prime}{ }_{1} \mid(0213) R$, and the minor presence of the $\beta_{1}$ phase, peak $(331)_{\beta 1}$ (Figure $\left.1 b\right)$. The structure of the alloy submitted to $1 / 2$ heating cycle (Figure 1 c) varied deeply in the participation of the aforementioned phases: the greater the participation of the martensite $\gamma_{1}^{\prime}$ phase, there was some increase in the participation of the high-temperature $\beta_{1}$ phase, (331) $\beta_{1}$, while the presence of the $\beta^{\prime}{ }_{1}$ and R-phases was less intensive.

The DSC analysis of monocrystalline $\mathrm{Cu}-13.7 \% \mathrm{Al}-4.2 \% \mathrm{Ni}$ alloy in the initial state (Figure 2) showed that on the second heating, the reverse RMT $\left(\beta^{\prime}{ }_{1}+\gamma^{\prime}{ }_{1}\right) \rightarrow \beta_{1}$ occurred in the range from +38.2 ${ }^{\circ} \mathrm{C}\left(\mathrm{A}_{\mathrm{s}}\right)$ to $+68.8^{\circ} \mathrm{C}\left(\mathrm{A}_{\mathrm{f}}\right)$ through an endothermic process with a phase transformation enthalpy of 9 $\mathrm{J} / \mathrm{g}$. The process developed an "on-set" mode from $+51.4{ }^{\circ} \mathrm{C}\left(\mathrm{A}_{\mathrm{o}}\right)$, presenting the peak temperature of $+54.7^{\circ} \mathrm{C}\left(\mathrm{A}_{\mathrm{p}}\right)$, where the heat flux was maximum. The process ended in an "off-set" mode at the temperature of $+60.4^{\circ} \mathrm{C}\left(\mathrm{A}_{\mathrm{of}}\right)$. On cooling of the alloy, the direct RMT $\beta_{1} \rightarrow\left(\beta^{\prime}{ }_{1}+\gamma^{\prime}{ }_{1}\right)$ occurs between $+51.4{ }^{\circ} \mathrm{C}\left(\mathrm{M}_{\mathrm{s}}\right)$ and $16.0^{\circ} \mathrm{C}\left(\mathrm{M}_{\mathrm{f}}\right)$, having on-set temperature peaks $47.7^{\circ} \mathrm{C}\left(\mathrm{M}_{\mathrm{o}}\right),+42{ }^{\circ} \mathrm{C}\left(\mathrm{M}_{\mathrm{p}}\right)$ and +32.6 ${ }^{\circ} \mathrm{C}\left(\mathrm{M}_{\mathrm{of}}\right)$, respectively, attributed to the exothermic process with a transformation enthalpy of $8.8 \mathrm{~J} / \mathrm{g}$. 


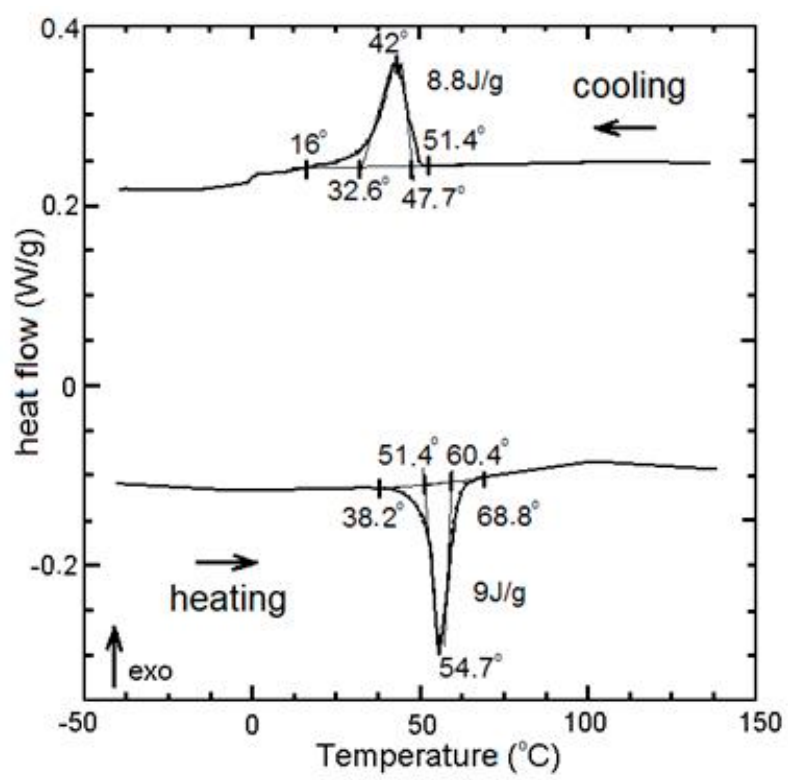

Figure 2. The DSC analysis of monocrystalline $\mathrm{Cu}-13.7 \% \mathrm{Al}-4.2 \% \mathrm{Ni}$ alloy in the initial state showed reverse heating and direct reversible martensitic transformations (RMT).

It is known that SME Cu-Al-Ni alloys can undergo a single transformation $\left(\beta_{1} \rightarrow \beta^{\prime}{ }_{1}\right.$ or $\beta_{1} \rightarrow$ $\left.\gamma^{\prime}{ }_{1}\right)$ or a mixed transformation $\left(\beta_{1} \rightarrow \gamma^{\prime}{ }_{1}+\beta^{\prime}{ }_{1}\right)$ depending on the composition of the alloy. In [24-29] it was confirmed that the mixed transformation $\left(\beta_{1} \rightarrow \gamma^{\prime}{ }_{1}+\beta^{\prime}{ }_{1}\right)$ takes place in the structure of $\mathrm{Cu}-\mathrm{Al}-\mathrm{Ni}$ alloys of approximately the same composition as the studied alloy. These martensitic transformations to $\gamma^{\prime}{ }_{1}$ or $\beta^{\prime}{ }_{1}$ structures have negligible energy difference so that sliding along the atomic layers can be implemented. Thus, the transformation from one compact structure to another is easily accomplished [3,30].

The DSC results show that during heating/cooling of the alloy, the critical RMT ranges were narrow, approximately $30.6{ }^{\circ} \mathrm{C}$ for $\mathrm{A}_{\mathrm{s}}-\mathrm{A}_{\mathrm{f}}$ and $35.4{ }^{\circ} \mathrm{C}$ for $\mathrm{M}_{\mathrm{s}}-\mathrm{M}_{\mathrm{f}}$. As a measure of thermal hysteresis, the difference among the peak critical temperatures $\left(\Delta T=A_{p}-M_{p}\right)$ was determined at approximately $12.7^{\circ} \mathrm{C}$ in the first thermal cycle [20-22]. According to References [3,24-29], RMT features can be deduced from the magnitude of the thermal hysteresis which is in good agreement with the results obtained, whereas the martensitic transformation $\beta_{1} \leftrightarrow\left(\beta^{\prime}{ }_{1}+\gamma^{\prime}{ }_{1}\right)$ presented hysteresis around $10^{\circ} \mathrm{C}$ (Figure 3).

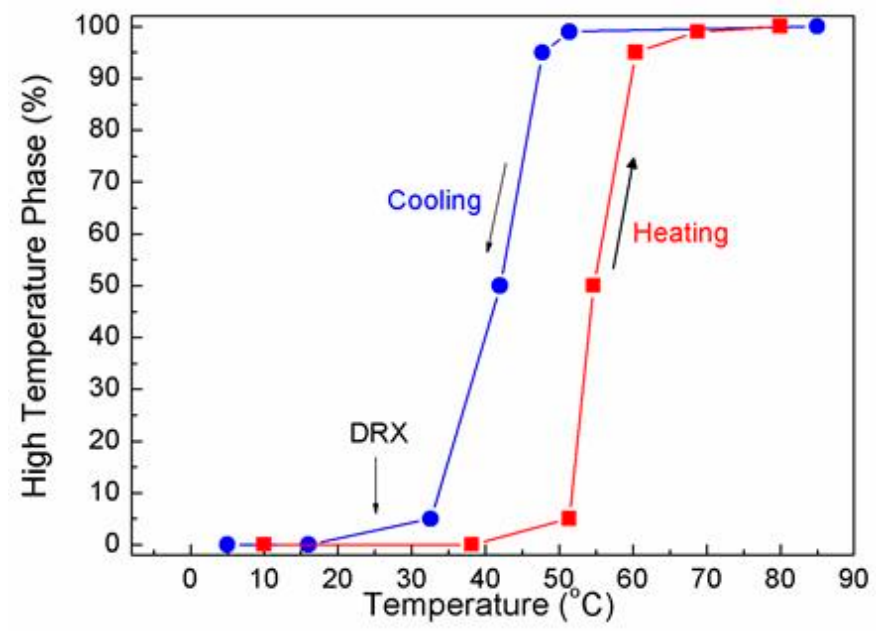

Figure 3. Schematic representation of the thermal hysteresis, showing the transformation $\beta_{1} \leftrightarrow\left(\beta^{\prime}{ }_{1}+\right.$ $\gamma_{1}^{\prime}$ ), presenting hysteresis around $10{ }^{\circ} \mathrm{C}$. 
3.2. Differential Scanning Calorimetry of the Monocrystalline Cu-13.7\% Al-4.2\% Ni Alloy after TCT under Loads

\subsubsection{Reverse RMT Curves during the First Cycle of DSC Analysis}

Thermal cycling-treated samples under loads were submitted to two thermal cycles in the DSC analysis. Firstly, the samples were cooled from RT. The reverse RMT curves obtained in the first DSC cycle of monocrystalline $\mathrm{Cu}-13.7 \% \mathrm{Al}-4.2 \% \mathrm{Ni}$ alloy submitted to TCT under load are shown in Figure 4. After TCT under loadings of $0.11 \mathrm{MPa}$ (Figure 4a) and $0.53 \mathrm{MPa}$ (Figure 4c), the reverse RMT peak was split into two. In contrast, at TCT under a load of $0.26 \mathrm{MPa}$, the reverse RMT curves of the alloy showed a single transformation peak; thus, structural imperfections accumulated during TCTs promote full RMT (Figure 4b).
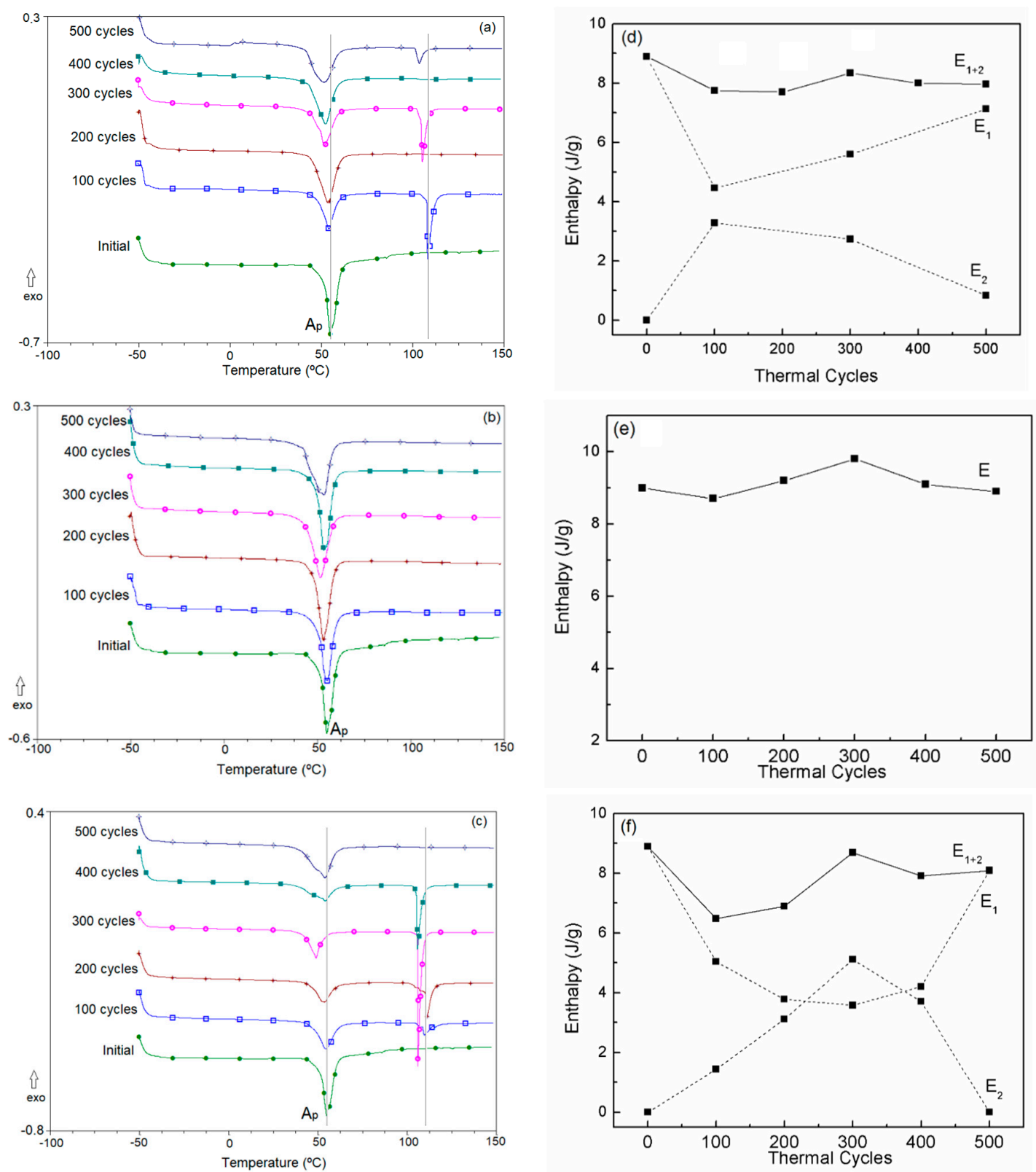

Figure 4. The reverse RMT curves (a-c) and reverse RMT enthalpies (E) (d-f) obtained in the first DSC cycle of monocrystalline Cu-13.7\% Al-4.2\% Ni alloy submitted to TCT under loadings of (a) $0.11 \mathrm{MPa}$, (b) $0.26 \mathrm{MPa}$, and (c) $0.53 \mathrm{MPa}$. 
This result becomes more evident when considering reverse RMT enthalpies (E) of the alloy after TCT under the loads of 0.11 (Figure $4 \mathrm{~d}$ ), 0.26 (Figure 4e), and $0.53 \mathrm{MPa}$ (Figure 4f), where $\mathrm{E}_{1}$ and $E_{2}$ are the enthalpy of the first and the second transformation peak, respectively; $E_{1+2}$ is the sum of the enthalpies.

It is interesting to monitor the evolution of the enthalpies $E_{1}$ and $E_{2}$. The value of $E_{2}$ tends to increase with an increase in the number of cycles up to 100 TCT (at $0.11 \mathrm{MPa}$ ) or up to 300 TCT (at $0.53 \mathrm{MPa}$ ) and decrease with a further increase in the number of TCTs under load. The value of enthalpy was entire in the case of TCTs under $0.26 \mathrm{MPa}$ (Figure 4e). The total enthalpy of the reverse transformation, in all tests, varied only slightly with the number of cycles.

An increase in the critical temperature range of complete transformation $\left(\beta^{\prime}{ }_{1}+\gamma^{\prime}{ }_{1}\right) \rightarrow \beta_{1}$ correlate with the accumulation of lattice distortions during TMR/TCT, possible structural imperfections, its decrease with "training", and the predominant orientation of martensitic lamellas. Apparently, the load at $0.11 \mathrm{MPa}$ was not large enough for "training" work, while the load at $0.53 \mathrm{MPa}$ promoted the lattice distortions and the accumulation of its imperfections and complicated the implementation of TMR for the bulk material in the temperature range adopted in the TCT. In other words, under 0.11 $\mathrm{MPa}$ and $0.53 \mathrm{MPa}$, the TCT was realized in conditions of incomplete RMT cycles.

In these tests, a load at $0.26 \mathrm{MPa}$ seemed to be sufficient to give rise to the reversible martensitic transformations during heating and cooling thus facilitating the "training" of the alloy during cyclic tests and maintaining a narrow range of TMR and did not stimulate the accumulation of defects in the alloy structure.

\subsubsection{Direct and Reverse RMT of the Monocrystalline Cu- $13.7 \%$ Al- $4.2 \%$ Ni Alloy Curves after TCT under Loads}

The DSC analysis of the alloy in the initial state showed that on heating, the reverse RMT $\beta^{\prime}{ }_{1} \rightarrow$ $\beta_{1}$ occurred in the range of $+38.2^{\circ} \mathrm{C}\left(\mathrm{A}_{\mathrm{s}}\right)$ to $+68.8^{\circ} \mathrm{C}\left(\mathrm{A}_{\mathrm{f}}\right)$ through an endothermic process: phase transformation enthalpy $\sim 9 \mathrm{~J} / \mathrm{g}$. The process developed from an on-set temperature of $+51.4^{\circ} \mathrm{C}\left(\mathrm{A}_{\mathrm{o}}\right)$ and was responsible for the peak at $+54.7^{\circ} \mathrm{C}\left(\mathrm{A}_{\mathrm{p}}\right)$, where the heat flux was maximum. The process ended in an "off-set" mode at $+60.4^{\circ} \mathrm{C}\left(\mathrm{A}_{\text {of }}\right)$. On cooling, the direct RMT, $\beta_{1} \rightarrow \beta^{\prime}{ }_{1}$, occurred in the temperature range of $+51.4^{\circ} \mathrm{C}\left(\mathrm{M}_{\mathrm{s}}\right)$ to $16.0^{\circ} \mathrm{C}\left(\mathrm{M}_{\mathrm{f}}\right)$, having an on-set, peak and off-set temperatures at $+47.7^{\circ} \mathrm{C}\left(\mathrm{M}_{\mathrm{o}}\right),+42{ }^{\circ} \mathrm{C}\left(\mathrm{M}_{\mathrm{p}}\right)$, and $+32.6^{\circ} \mathrm{C}\left(\mathrm{M}_{\mathrm{of}}\right)$, respectively, associated with the exothermic process with a transformation enthalpy of $8.8 \mathrm{~J} / \mathrm{g}$ (Figure 2).

The effect of TCTs under the loads of $0.11,0.26$, and $0.53 \mathrm{MPa}$ on the RMT characteristics of the monocrystalline $\mathrm{Cu}-13.7 \% \mathrm{Al}-4.2 \% \mathrm{Ni}$ alloy as determined by DSC analysis during cooling and 2nd heating without load and manifested in the displacement of critical temperatures and intervals is shown in Figures 5-7.
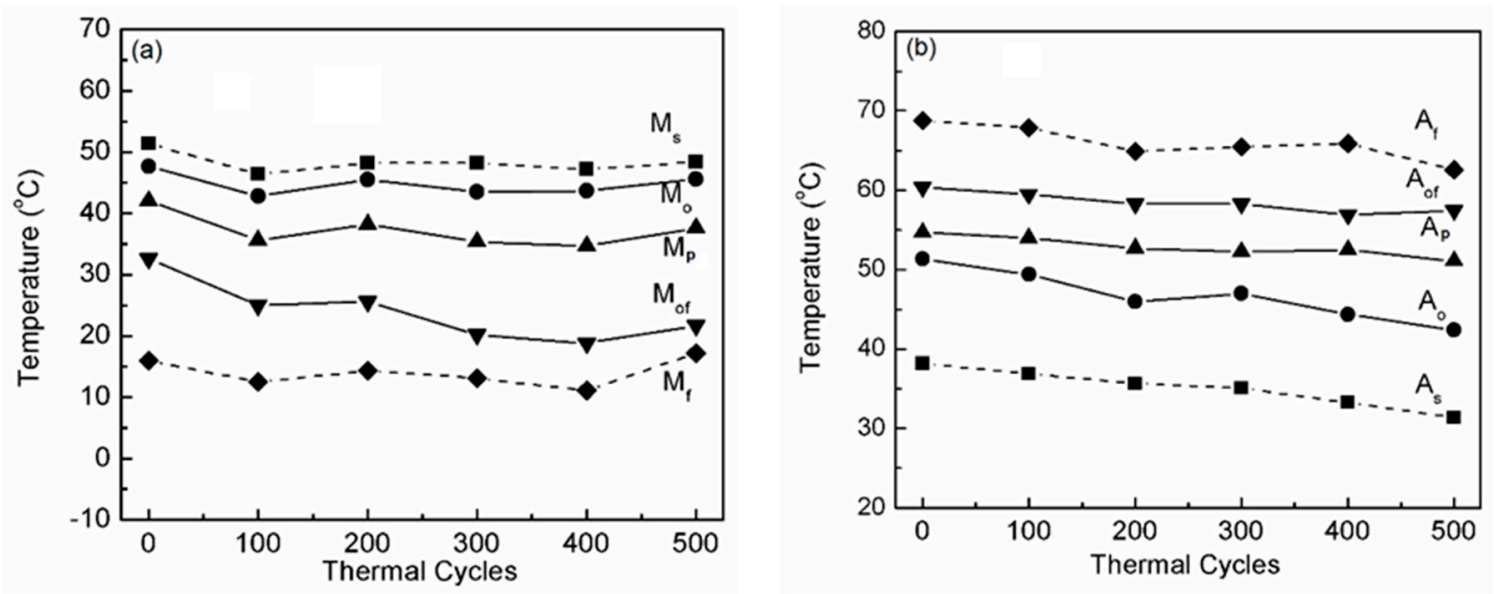

Figure 5. RMT critical temperatures obtained by DSC analysis during (a) cooling and (b) 2nd heating without loading of the monocrystalline $\mathrm{Cu}-13.7 \% \mathrm{Al}-4.2 \% \mathrm{Ni}$ alloy after TCT under the load of $0.11 \mathrm{MPa}$. 

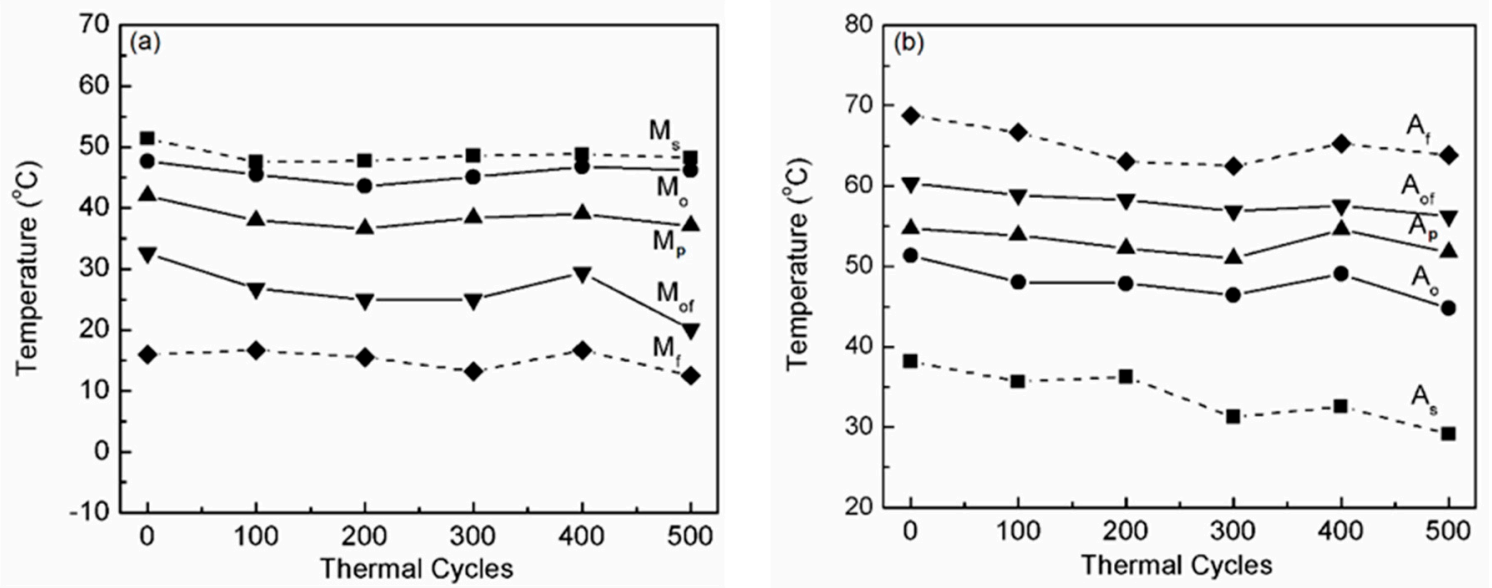

Figure 6. RMT critical temperatures obtained by DSC analysis during (a) cooling and (b) 2nd heating without loading of the monocrystalline $\mathrm{Cu}-13.7 \% \mathrm{Al}-4.2 \% \mathrm{Ni}$ alloy after TCT under the load of $0.26 \mathrm{MPa}$.
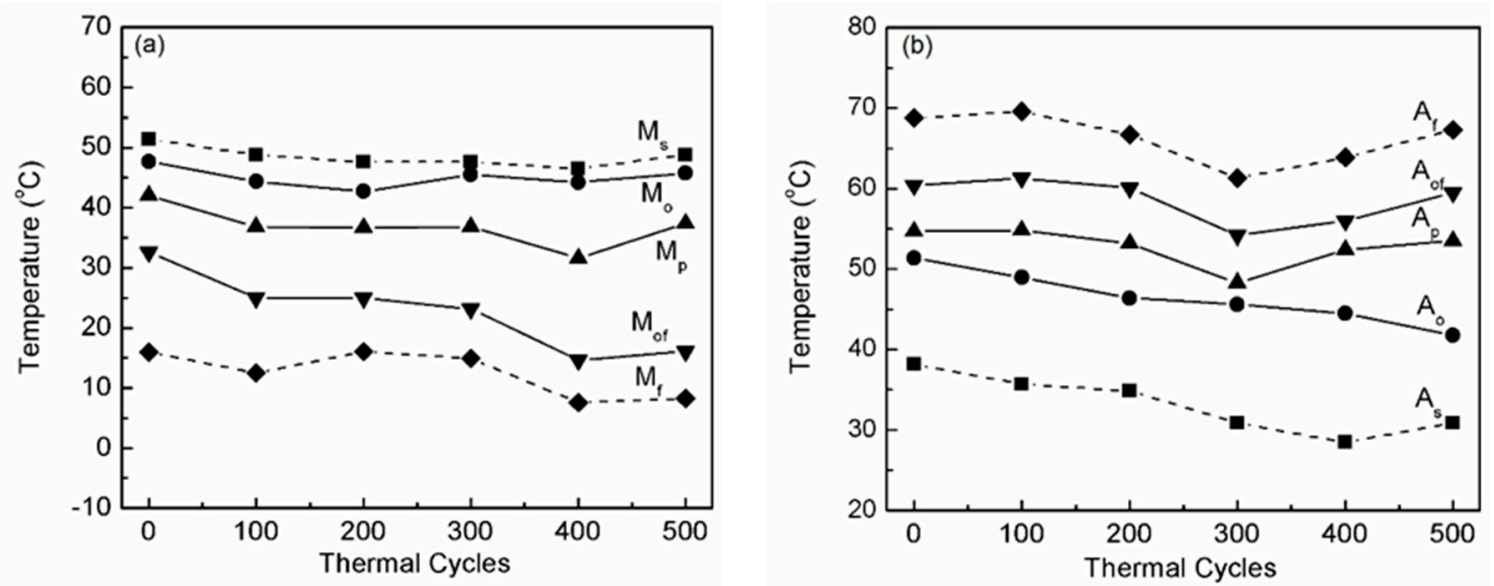

Figure 7. RMT critical temperatures obtained by DSC analysis during (a) cooling and (b) 2nd heating without loading of the monocrystalline $\mathrm{Cu}-13.7 \% \mathrm{Al}-4.2 \% \mathrm{Ni}$ alloy after TCT under the load of $0.53 \mathrm{MPa}$.

After TCTs under the load of $0.11 \mathrm{MPa}$, the critical temperatures of intensive RMT, mainly $\mathrm{M}_{\text {of }}$ and $\mathrm{A}_{\mathrm{O}}$, moved slightly to lower values, thus justifying the increase in the intensive RMT intervals. The intensive direct RMT ranges, $\mathrm{M}_{\mathrm{o}}-\mathrm{M}_{\mathrm{p}}$ and $\mathrm{M}_{\mathrm{o}}-\mathrm{M}_{\mathrm{of}}$, increased from 5.7 and $15.1^{\circ} \mathrm{C}$ (in the first cycle without loading) to 8.1 and $23.3^{\circ} \mathrm{C}$ (300 TCTs) and remained almost constant at 8 and $23.9^{\circ} \mathrm{C}(500 \mathrm{TCTs})$. The intensive intervals of reverse RMT, $\mathrm{A}_{\mathrm{o}}-\mathrm{A}_{\mathrm{p}}$ and $\mathrm{A}_{\mathrm{o}}-\mathrm{A}_{\mathrm{of}}$, during the first thermal cycle, determined as 3.3 and $9{ }^{\circ} \mathrm{C}$, increased to 8.7 and $15.1^{\circ} \mathrm{C}$, respectively, when it came to 500 TCTs (Figure 5).

After TCTs under the load of $0.26 \mathrm{MPa}$, the critical temperatures of intensive RMTs shifted slightly to lower values, up to $300 \mathrm{TCTs}$; then, the intensive temperatures remained constant and/or increased in value. The intensive direct RMT ranges, $\mathrm{M}_{\mathrm{o}}-\mathrm{M}_{\mathrm{p}}$ and $\mathrm{M}_{\mathrm{o}}-\mathrm{M}_{\mathrm{of}}$, increased from 5.7 and $15.1{ }^{\circ} \mathrm{C}$ (in the first cycle without loading) to 9.1 and $26.1^{\circ} \mathrm{C}$ (500 TCTs). The intensive intervals of reverse RMT, $\mathrm{A}_{\mathrm{o}}-\mathrm{A}_{\mathrm{p}}$ and $\mathrm{A}_{\mathrm{o}}-\mathrm{A}_{\mathrm{of}}$, during the first thermal cycle were determined as 3.3 and $9{ }^{\circ} \mathrm{C}$ and increased to 7 and $11.5^{\circ} \mathrm{C}(500 \mathrm{TCTs})$ (Figure 6).

After TCTs under a load of $0.53 \mathrm{MPa}$, the critical temperatures of intensive direct RMT, $\mathrm{M}_{\mathrm{p}}$ and $\mathrm{M}_{\mathrm{of}}$, moved slightly to lower values, up to $400 \mathrm{TCTs}$, and remained the same. The intensive direct RMT intervals, $\mathrm{M}_{\mathrm{o}}-\mathrm{M}_{\mathrm{p}}$ and $\mathrm{M}_{\mathrm{o}}-\mathrm{M}_{\mathrm{of}}$, increased from 5.7 and $15.1^{\circ} \mathrm{C}$ (the first cycle without loading) to 8.4 and $29.7^{\circ} \mathrm{C}$ after 500 TCTs. The critical temperatures of intensive reverse RMT, $\mathrm{A}_{\mathrm{o}}, \mathrm{A}_{\mathrm{p}}$, and $\mathrm{A}_{\mathrm{of}}$, moved slightly to lower values, up to 300 cycles, and tended to increase afterward. The intensive ranges of reverse RMT, $A_{o}-A_{p}$ and $A_{o}-A_{o f}$, during the first thermal cycle were determined as 3.3 and 
$9{ }^{\circ} \mathrm{C}$, then decreased to 2.7 and $8.6{ }^{\circ} \mathrm{C}$ after 300 cycles, and finally increased to 11.7 and $17.5^{\circ} \mathrm{C}$ with 500 cycles TCT (Figure 7).

The difference among the peak critical temperatures $\left(\Delta T=A_{p}-M_{p}\right)$, as a measure of the thermal hysteresis amplitude, was determined as approximately $12.7^{\circ} \mathrm{C}$ in the first thermal cycle of the investigated alloy. The changes in peak temperatures, $\mathrm{A}_{\mathrm{p}}$ and $\mathrm{M}_{\mathrm{p}}$, after TCT under load, alter the magnitude of the thermal hysteresis as observed in Figure 8.

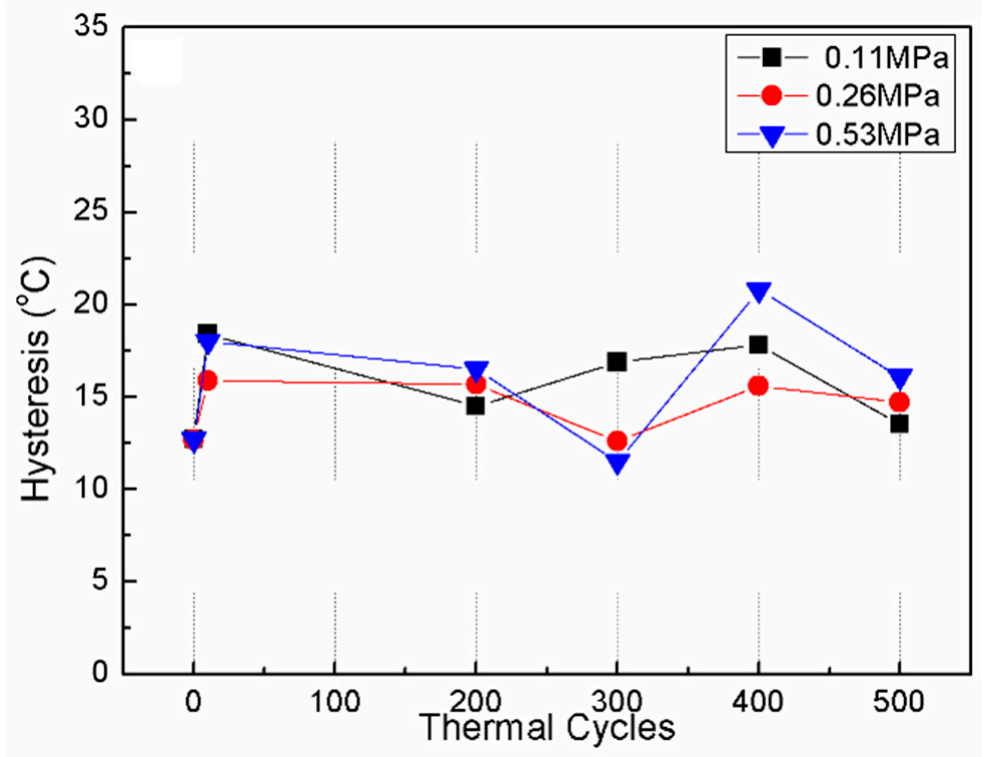

Figure 8. Values of thermal hysteresis as a function of applied TCT of the monocrystalline $\mathrm{Cu}-13.7 \%$ Al-4.2\% Ni alloy.

\subsection{XRD Analysis of the Monocrystalline Cu-13.7\% Al-4.2\% Ni Alloy after TCT under Load}

\subsubsection{XRD Analysis after TCT under Loading of $0.11 \mathrm{MPa}$ Ending with the $1 / 2$ Cooling Cycle}

The $\mathrm{Cu}-13.7 \%$ Al-4.2\% Ni alloy diffractograms after TCT, terminated with the $1 / 2$ cooling cycle (under load) and the 1/2 heating cycle (without the load), are shown in Figure 9a,b. As can be seen, the phase compositions of these alloys differ significantly.

The diffractogram of $\mathrm{Cu}-13.7 \% \mathrm{Al}-4.2 \% \mathrm{Ni}$ alloy after TCTs under the load of $0.11 \mathrm{MPa}$ finished with the $1 / 2$ cooling cycle exhibited four metastable phases (Figure 9 a). The major phase was martensite $\beta^{\prime}{ }_{1}$, an ordered $\mathrm{AlCu}_{3}$-type phase [31], peaks $\beta^{\prime}{ }_{1}$ and $\beta^{\prime}{ }_{1}$. The other martensitic phase $\gamma^{\prime}{ }_{1}$, ordered $\mathrm{Cu}_{3}$ Ti-type phase $[1,3,15]$ was identified with the peaks $(011) \gamma^{\prime}{ }_{1},(212) \gamma^{\prime}{ }_{1}$, and $(111) \gamma^{\prime}{ }_{1}$. The high temperature phase $\beta_{1}$, ordered $\mathrm{BiF}_{3}$-type phase [14] was detected by its $(331)_{\beta 1}$ peak. The $\mathrm{Al}_{7} \mathrm{Cu}_{4} \mathrm{Ni}$ phase with rhombohedral structure [16,17], called the R-phase in our works [18-22], is represented by the (107)R peak as well as the peak corresponding to the plane of coherence between the phases $\beta^{\prime}{ }_{1}$ and $\mathrm{R}, \beta^{\prime}{ }_{1} \mid(0213) \mathrm{R}$.

With the accumulation of 100 cycles, the major phase, martensite $\beta^{\prime}{ }_{1}$, was identified by intense $\beta^{\prime}{ }_{1}$ and $\beta^{\prime}{ }_{1}$ peaks; the moderate (107)R peak corresponded to the R-phase. A peak related to the plane of coherence between the martensitic $\beta^{\prime}{ }_{1}$ phase and $R, \beta^{\prime}{ }_{1} \mid(0213) R$ was detected. The other peaks, $(011) \gamma_{1}^{\prime}{ }_{1},(111) \gamma_{1}^{\prime}{ }_{1},(212) \gamma_{1}^{\prime}{ }_{1}$ and (331) $\beta_{1}$, had low intensity.

With the accumulation of 200 thermal cycles, the diffractogram shows minor changes in structure, reducing only the intensity of the coherence planes peak $\beta^{\prime}{ }_{1} \mid(0213) R$ and the R-phase peak (107)R. The martensitic $\beta^{\prime}{ }_{1}$ phase was still observed, indicating its temperature/thermal stability. After 300 TCTs, the accumulated distortions promoted changes in the martensitic structure, and the induced martensitic transformation $\beta^{\prime}{ }_{1} \rightarrow \gamma^{\prime}{ }_{1}$ was observed. This TCT treatment promotes the greater stability 
of the martensitic phase $\gamma^{\prime}{ }_{1}$, determined by $(011) \gamma^{\prime}{ }_{1}$ and $(212) \gamma_{1}^{\prime}{ }_{1}$ peaks. The plane of coherence between the martensitic phases $\beta^{\prime}{ }_{1}$ and $R, \beta^{\prime}{ }_{1} \mid(0213) R$, display moderate intensity.

The treatment of 400 TCTs once again results in major participation of martensite phase $\beta^{\prime}{ }_{1}$ determined through the $\beta^{\prime}{ }_{1}$ - peaks. After 500 TCTs the XRD patterns reveal intense coherent planes $\beta^{\prime}{ }_{1} \mid(0213) R$ peak, as well as $\beta^{\prime}{ }_{1}$ and $\beta^{\prime}{ }_{1}$ peaks, corresponding to martensitic $\beta^{\prime}{ }_{1}$. The (107)R peak, referring to phase $R$, has moderate intensity. The other peaks, $(011) \gamma^{\prime}{ }_{1},(111) \gamma^{\prime}{ }_{1},(212) \gamma^{\prime}{ }_{1}$ and (331) $\beta_{1}$, have low intensity.

\subsubsection{XRD Analysis after TCT under Loading of $0.11 \mathrm{MPa}$ Ending with $1 / 2$ Heating Cycle}

With the accumulation of 100 cycles, the major phase is martensitic $\beta^{\prime}{ }_{1}$, represented by $(10-1-2) \beta^{\prime}{ }_{1}$ and (20-2-4) $\beta^{\prime}{ }_{1}$ peaks. The peaks of coherent plane, $\beta^{\prime}{ }_{1} \mid(0213) R$, of the R-phase, (107)R, and of the high temperature phase $\beta_{1},(331) \beta_{1}$, display moderate intensity. The martensitic phase $\gamma^{\prime}{ }_{1}$ is detected by its low intensity peaks $(011) \gamma_{1}^{\prime}{ }_{1},(111) \gamma^{\prime}{ }_{1}$, and $(212) \gamma_{1}^{\prime}$, Figure $9 \mathrm{~b}$.

With the accumulation of 200 TCTs, the amount of martensite $\beta^{\prime}{ }_{1}$ decreased and martensite $\gamma^{\prime}{ }_{1}$ increased, exhibiting $(011)_{\gamma^{\prime} 1}$ and $(212)_{\gamma^{\prime} 1}$ peaks. The peak of the coherent plane $\beta^{\prime}{ }_{1} \mid(0213) R$ was intensive, whereas the R-phase peak, (107)R, exhibited moderate intensity.

After $300 \mathrm{TCTs}$, the XRD pattern changed slightly, displaying higher participation of the martensitic $\beta^{\prime}{ }_{1}$ phase, and the (10-1-2) $\beta^{\prime}{ }_{1}$ and (20-2-4) $\beta^{\prime}{ }_{1}$ peaks reappeared.

After 200 and 300 TCTs, the induced martensitic transformation $\beta^{\prime}{ }_{1} \rightarrow \gamma^{\prime}{ }_{1}$ was incomplete (Figure $9 \mathrm{~b}$ ). The energy difference among these martensitic structures was negligible, and the sliding along of the atomic layers could be implemented. Thus, the transformation from one close-packed structure to the other was easily performed, mostly during thermal cycling $[3,30]$.

The 400 TCTs induced considerable participation of the coherent plane $\beta^{\prime}{ }_{1} \mid(0213) R$ and of the martensitic $\beta^{\prime}{ }_{1}$ (10-1-2) $\beta^{\prime}{ }_{1}$ and (20-2-4) $\beta^{\prime}{ }_{1}$ peaks. Reorientation of the high-temperature phase $\beta_{1}$ was revealed by an intensive (400) $\beta_{1}$ peak. The peaks associated with the $\gamma^{\prime}{ }_{1}$ and R-phases, $(011) \gamma^{\prime}{ }_{1}$, (212) $\gamma^{\prime}{ }_{1}$, and (107)R were less intensive.

After 500 TCTs, the XRD pattern displayed a higher amount of the martensitic $\beta^{\prime}{ }_{1}$ phase, represented by (10-1-2) $\beta^{\prime}{ }_{1}$ and (20-2-4) $\beta^{\prime}{ }_{1}$ peaks, a characteristic peak of the R-phase, (107)R, but small participation of the coherent plane $\beta^{\prime}{ }_{1} \mid(0213) R$. 

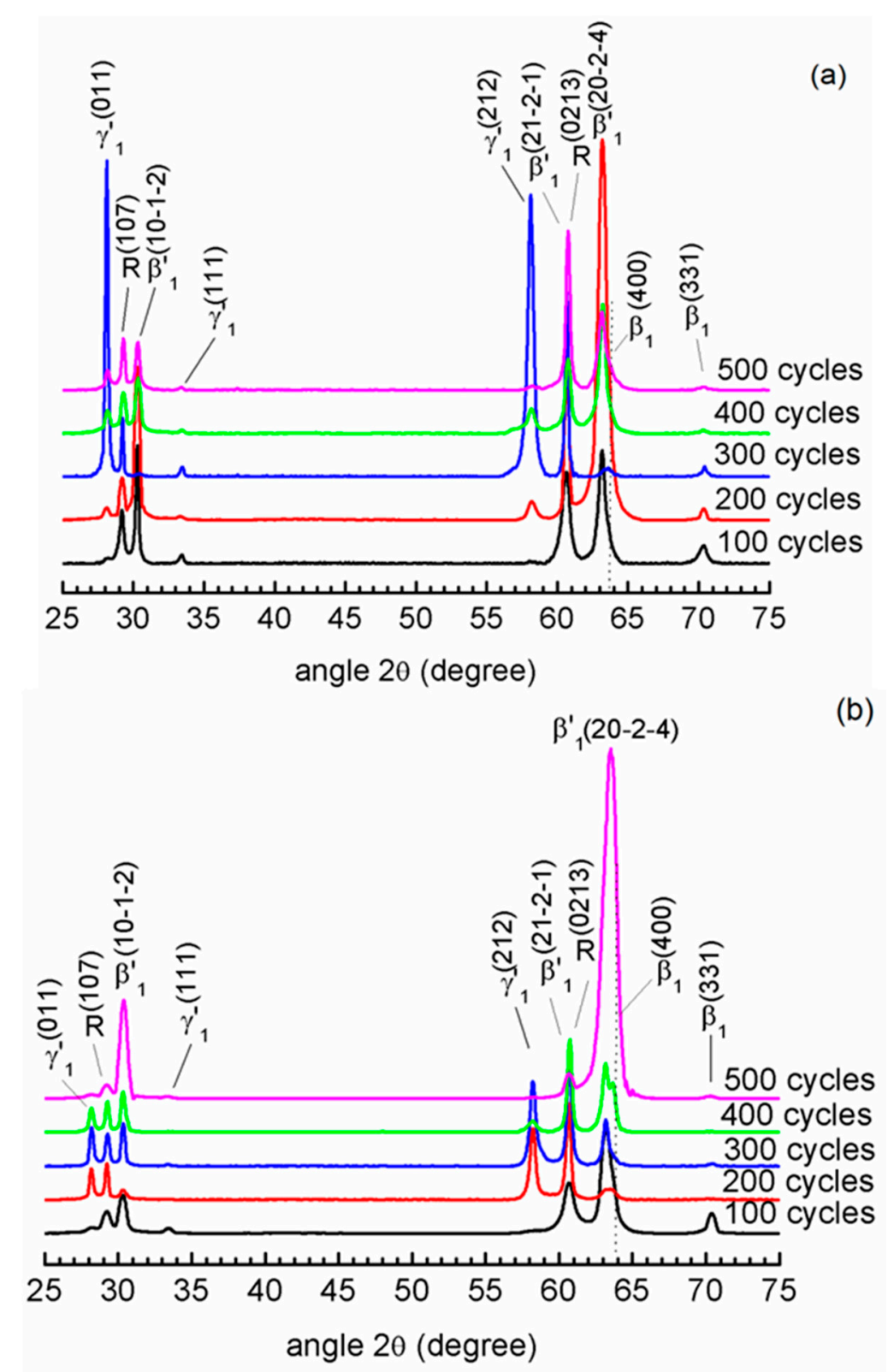

Figure 9. Diffractograms of $\mathrm{Cu}-13.7 \% \mathrm{Al}-4.2 \% \mathrm{Ni}$ alloy after TCTs under loading of $0.11 \mathrm{MPa}$ finished with the (a) $1 / 2$ cooling cycle and (b) $1 / 2$ heating cycle.

\subsubsection{XRD Analysis after TCT under Loading of $0.26 \mathrm{MPa}$ Ending with $1 / 2$ Cooling Cycle}

Figure 10a shows XRD patterns of $\mathrm{Cu}-13.7 \% \mathrm{Al}-4.2 \% \mathrm{Ni}$ alloy after TCTs under the load of $0.26 \mathrm{MPa}$ ending with the $1 / 2$ cooling cycle (under load). After $100 \mathrm{TCTs}$, the pattern exhibited a major peak corresponding to the $\beta_{1}$ phase, (331) $\beta_{1}$; the peak corresponding to the coherent planes $\beta^{\prime}{ }_{1}$ with $R$, $\beta^{\prime}{ }_{1} /(0213) \mathrm{R}$, was detected with moderate intensity, while peaks of the martensitic $\gamma^{\prime}{ }_{1},(111)_{\gamma^{\prime}{ }^{\prime} \text {, and of }}$ the R-phase, $(107)_{R}$, had lower intensity. 

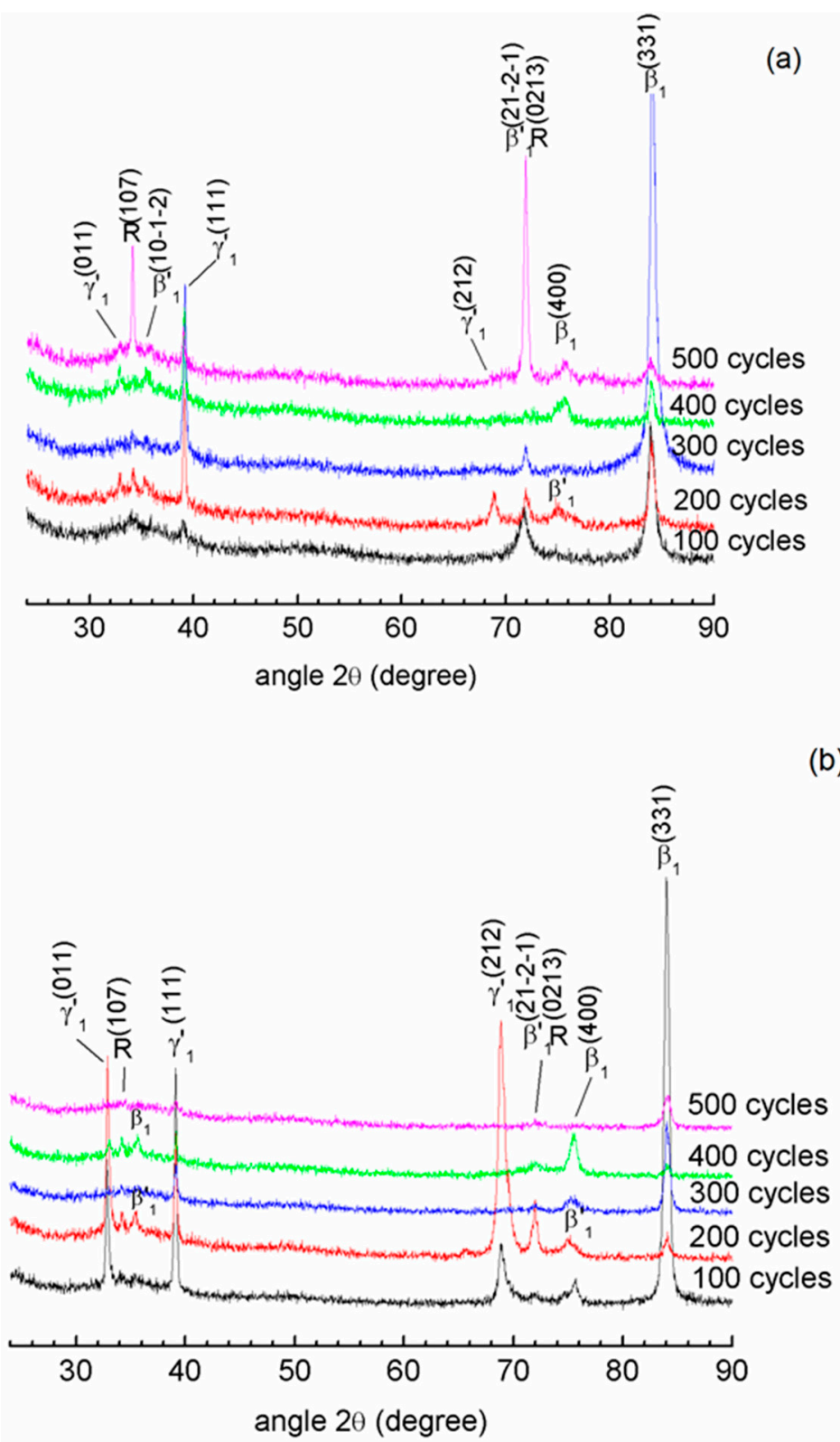

Figure 10. Diffractograms of $\mathrm{Cu}-13.7 \% \mathrm{Al}-4.2 \% \mathrm{Ni}$ alloy after TCTs under loading of $0.26 \mathrm{MPa}$ finished with the (a) $1 / 2$ cooling cycle and (b) $1 / 2$ heating cycle.

With the accumulation of 200 TCTs, considerable participation by the martensite $\gamma_{1}^{\prime}{ }_{1},(111) \gamma^{\prime}{ }_{1}$, $(011) \gamma^{\prime}{ }_{1}$, and (212) $\gamma_{1}^{\prime}$ peaks and of the high-temperature phase $\beta_{1},(331) \beta_{1}$ peak, was observed. The $\beta^{\prime}{ }_{1}$ martensite, with the less intensive (10-1-2) $\beta^{\prime}{ }_{1}$ and (20-2-4) $\beta^{\prime}{ }_{1}$ peaks, as well as the R-phase, $(107) \mathrm{R}$, and the coherent plane, $\beta^{\prime}{ }_{1} \mid(0213) R$, were also detected. After 300 TCTs, the high-temperature $\beta_{1}$ phase displayed an intensive (331) $\beta_{1}$ peak. The martensite $\gamma^{\prime}{ }_{1}$ was detected by a moderate intensity $(111) \gamma^{\prime}{ }_{1}$ peak, while the peak corresponding to the coherent plane between the phases $\beta^{\prime}{ }_{1}$ and $R, \beta^{\prime}{ }_{1} \mid(0213) R$, had lower intensity.

With the accumulation of $400 \mathrm{TCTs}$, the XRD pattern indicated greater participation by the martensite $\gamma^{\prime}{ }_{1}$ and high-temperature $\beta_{1}$ phase as represented by $(111) \gamma^{\prime}{ }_{1},(011) \gamma^{\prime}{ }_{1},(200) \beta_{1},(400) \beta_{1}$, and (331) $\beta_{1}$ peaks. The R-phase peak, (107)R, had a small intensity. After 500 TCTs, the XRD pattern revealed the R-phase, as a major phase, represented by intensive (107)R and $\beta^{\prime}{ }_{1} \mid(0213) \mathrm{R}$ peaks. The other $(011) \gamma_{1}^{\prime}{ }_{1},(018) R,(111) \gamma_{1}^{\prime}{ }_{1},(400) \beta_{1}$, and (331) $\beta_{1}$ peaks had lower intensity. 


\subsubsection{XRD Analysis after TCT under Loading of $0.26 \mathrm{MPa}$ Ending with $1 / 2$ Heating Cycle}

The Cu-13.7\% Al-4.2\% Ni alloy XRD patterns after TCTs under $0.26 \mathrm{MPa}$ load finished with the $1 / 2$ heating cycle are shown in Figure 10b. With the accumulation of 100 cycles, high-temperature phase $\beta_{1}$ displayed (331) $\beta_{1}$ and (400) $\beta_{1}$ peaks, and the martensitic $\gamma_{1}^{\prime}$ phase was detected by its (011) $\gamma^{\prime}{ }_{1}$, $(111) \gamma_{1}^{\prime}$, and $(212) \gamma_{1}^{\prime}$ peaks.

The accumulation of 200 TCTs favored the greater participation by martensite $\gamma^{\prime}{ }_{1}$, detected by $(111) \gamma^{\prime}{ }_{1},(011) \gamma^{\prime}{ }_{1}$, and $(212) \gamma_{1}^{\prime}{ }_{1}$ peaks. The other phases displayed $(107) \mathrm{R},(10-1-2) \beta^{\prime}{ }_{1},(20-2-4) \beta^{\prime}{ }_{1}$ $\beta^{\prime}{ }_{1} \mid(0213) R$, and (331) $\beta_{1}$ peaks with lower intensity. After 300 TCTs, the considerable participation of the high-temperature $\beta_{1}$ phase revealed by (331) $\beta_{1}$ and (400) $\beta_{1}$ peaks were observed. The martensite $\gamma^{\prime}{ }_{1}$ was detected by its moderate intensity peak, $(111) \gamma^{\prime}{ }_{1}$, while the phase $\mathrm{R}$ peaks, (107)R, and the coherent plane between the phases $\beta^{\prime}{ }_{1}\left|\mathrm{R}, \beta^{\prime}{ }_{1}\right|(0213) \mathrm{R}$, showed low intensity.

Accumulation of 400 TCTs resulted in the greater participation by the high-temperature phase $\beta_{1}$ as represented by (200) $\beta_{1},(400) \beta_{1}$, and (331) $\beta_{1}$ peaks. The martensite $\gamma^{\prime}{ }_{1}$ displayed moderate intensity $(011) \gamma_{1}^{\prime}{ }_{1}$ and (111) $\gamma^{\prime}{ }_{1}$ peaks. The phase R peak, (107)R, and the plane of coherence between phases $\beta^{\prime}{ }_{1}\left|\mathrm{R}, \beta^{\prime}{ }_{1}\right|(0213) \mathrm{R}$, were revealed by lower intensity.

After 500 TCTs, the XRD pattern indicated the high-temperature phase $\beta_{1}$ as a major phase, identified with (331) $\beta_{1}$ peak. Low-intensity (107)R, (111) $\gamma^{\prime}{ }_{1}$, and $\beta^{\prime}{ }_{1} \mid(0213) R$ peaks corresponded to minor phases.

\subsubsection{XRD Analysis after TCT under Loading of $0.53 \mathrm{MPa}$ Ending with $1 / 2$ Cooling Cycle}

$\mathrm{Cu}-13.7 \% \mathrm{Al}-4.2 \% \mathrm{Ni}$ alloy diffractograms after TCT under the load of $0.53 \mathrm{MPa}$ finished with the $1 / 2$ cooling cycle are shown in Figure 11a. With the accumulation of 100 TCTs, the prominent participation of the martensite $\beta^{\prime}{ }_{1}$ was represented by high (10-1-2) $\beta^{\prime}{ }_{1}$ and (20-2-4) $\beta^{\prime}{ }_{1}$ peaks as well as by the coherent plane $\beta^{\prime}{ }_{1} \mid(0213) \mathrm{R}$ between $\beta^{\prime}{ }_{1}$ and R-phases and the (107)R peak of the R-phase. The $(011) \gamma_{1}^{\prime}{ }_{1},(111) \gamma^{\prime}{ }_{1}$, and (212) $\gamma_{1}^{\prime}$ peaks of martensite $\gamma_{1}^{\prime}$ and the (331) $\beta_{1}$ peak of the high-temperature $\beta_{1}$ phase showed moderate intensity, representing smaller participation by these phases. With the accumulation of $200 \mathrm{TCTs}$, the coherent plane $\beta^{\prime}{ }_{1} \mid(0213) \mathrm{R}$ peak became higher, displaying the greater participation of $\beta^{\prime}{ }_{1} \mid R$. The participation of the martensitic $\gamma^{\prime}{ }_{1}$ and $\beta^{\prime}{ }_{1}$ phases, as well as R-phase, were detected by the moderate intensity peaks: $(011) \gamma^{\prime}{ }_{1},(111) \gamma^{\prime}{ }_{1},(212) \gamma^{\prime}{ }_{1},(10-1-2) \beta^{\prime}{ }_{1},(20-2-4) \beta^{\prime}{ }_{1}$, and (107)R. The (331) $\beta_{1}$ peak of the high-temperature $\beta_{1}$ phase had the lowest intensity.

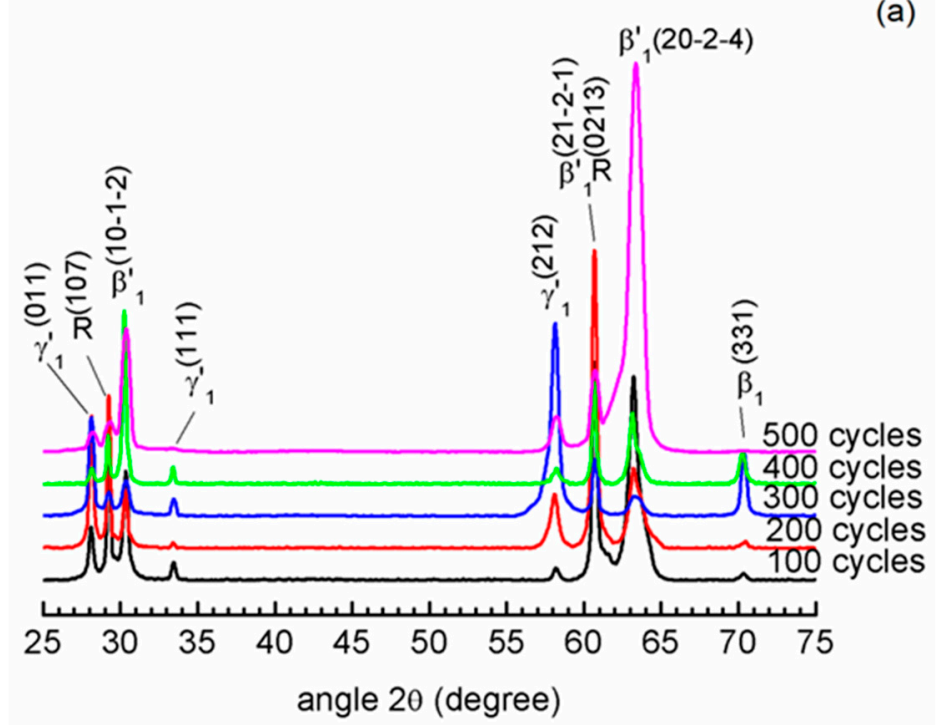

Figure 11. Cont. 


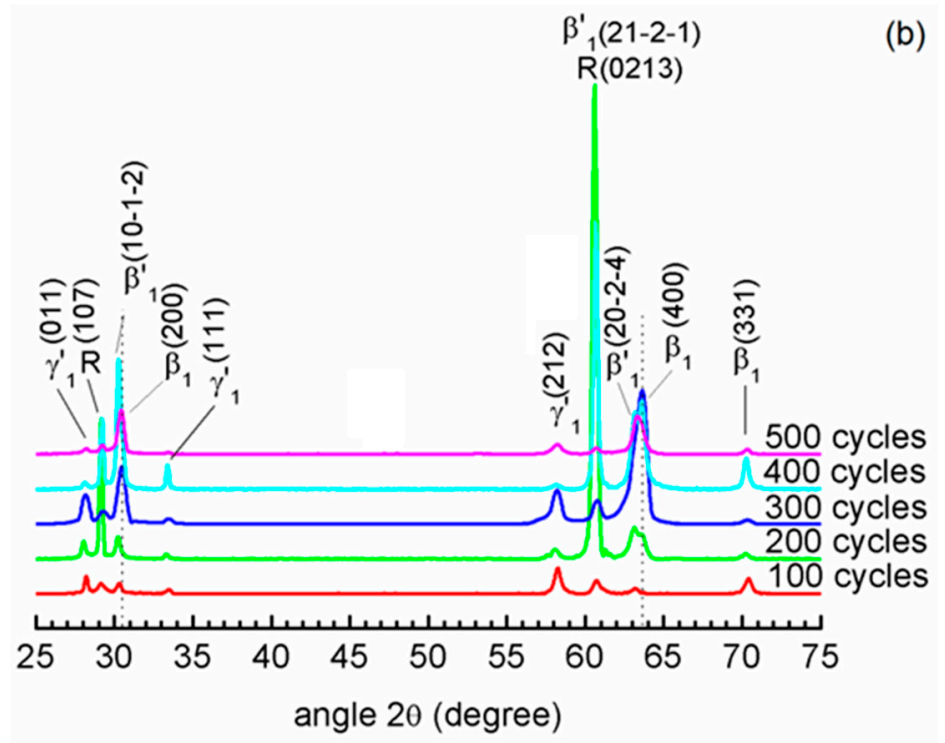

Figure 11. Diffractograms of $\mathrm{Cu}-13.7 \% \mathrm{Al}-4.2 \% \mathrm{Ni}$ alloy after TCTs under loading of $0.53 \mathrm{MPa}$ finished with the (a) $1 / 2$ cooling cycle and (b) $1 / 2$ heating cycle.

The 300 cycle TCTs promoted greater stability of the martensite $\gamma^{\prime}{ }_{1}$ identified by its $(011) \gamma_{1}{ }_{1}$ and $(212) \gamma_{1}^{\prime}$ peaks. The coherent plane $\beta^{\prime}{ }_{1} \mid(0213) R$ peak between the martensitic phases $\beta^{\prime}{ }_{1}$ and $R$, and (331) $\beta_{1}$ peak of the high-temperature phase $\beta_{1}$ were detected with moderate intensity. The $(10-1-2) \beta^{\prime}{ }_{1},(20-2-4) \beta^{\prime}{ }_{1}$, and (107)R peaks were revealed with low intensity. After 400 cycles, the amount of martensitic $\beta^{\prime}{ }_{1}$ phase increased, exhibiting intensive peaks (10-1-2) $\beta^{\prime}{ }_{1}$ and (20-2-4) $\beta^{\prime}{ }_{1}$. The coherent plane $\beta^{\prime}{ }_{1} \mid(0213) R$ peak between the martensitic $\beta^{\prime}{ }_{1}$ and R-phases, (331) $\beta_{1}$ peak of the high-temperature $\beta_{1}$ phase, and the (107)R peak of R-phase were detected with moderate intensity. Martensite $\gamma_{1}^{\prime}{ }_{1}$ was detected in a small amount.

After 500 TCTs, the XRD pattern exhibited the prominent participation of the martensitic $\beta^{\prime}{ }_{1}$ phase by its (10-1-2) $\beta^{\prime}{ }_{1}$ and (20-2-4) $\beta^{\prime}{ }_{1}$ peaks while decreasing all other peaks related to $\gamma^{\prime}{ }_{1}, R$, and $\beta^{\prime}{ }_{1} \mid$ R-phases.

\subsubsection{XRD Analysis after TCT under Loading of $0.53 \mathrm{MPa}$ Ending with $1 / 2$ Heating Cycle}

The $\mathrm{Cu}-13.7 \% \mathrm{Al}-4.2 \% \mathrm{Ni}$ alloy diffractograms after TCTs finished with the $1 / 2$ heating cycle are shown in Figure 11b. After 100 cycles, major participation by the martensitic $\gamma^{\prime}{ }_{1}$ phase, identified by intensive (011) $\gamma^{\prime}{ }_{1},(111) \gamma^{\prime}{ }_{1},(212) \gamma^{\prime}{ }_{1}$ peaks was observed. The $R, \beta^{\prime}{ }_{1}, \beta^{\prime}{ }_{1} \mid R$, and $\beta_{1}$ phases were detected by moderate intensity (107)R, (10-1-2) $\beta^{\prime}{ }_{1},(20-2-4) \beta^{\prime}{ }_{1}, \beta^{\prime}{ }_{1} \mid(0213) \mathrm{R}$, and (331) $\beta_{1}$ peaks. With the accumulation of $200 \mathrm{TCTs}$, the amount of $\gamma^{\prime}{ }_{1}$ martensite decreased while the participation of the coherent plane between the martensitic $\beta^{\prime}{ }_{1}$ and R-phases, $\beta^{\prime}{ }_{1} \mid(0213) \mathrm{R}$, increased. Associated with the $\mathrm{R}$-phase, the (107)R peak was detected with moderate intensity. There was an insignificant amount of the other aforementioned phases.

After 200 cycles, the martensite $\beta^{\prime}{ }_{1}$ stabilized, its peaks $(10-1-2) \beta^{\prime}{ }_{1}$ and (20-2-4) $\beta^{\prime}{ }_{1}$ shifted slightly, thus developing a strong coherence with the high-temperature phase $\beta_{1}$, represented by (200) $\beta_{1}$ and (400) $\beta_{1}$ peaks. After 400 TCTs, the $R, \gamma^{\prime}{ }_{1}$, and $\beta_{1}$ phases were detected in smaller amounts.

\subsection{Optical Microscopy after TCT under Loading}

The structure of $\mathrm{Cu}-13.7 \% \mathrm{Al}-4.2 \% \mathrm{Ni}$ alloy after TCTs under the load of $0.11 \mathrm{MPa}$ is shown in Figures 12 and 13. In the initial state, the alloy demonstrated a surface structure composed of martensitic blocks: a central block and four peripheral blocks. No significant changes were detected by optical microscopy at the end of treatment and 1/2 cooling cycle (Figure 12a,c,e and Figure 13a,c) or 1/2 heating cycle (Figure 12b,d,f and Figure 13b,d). 


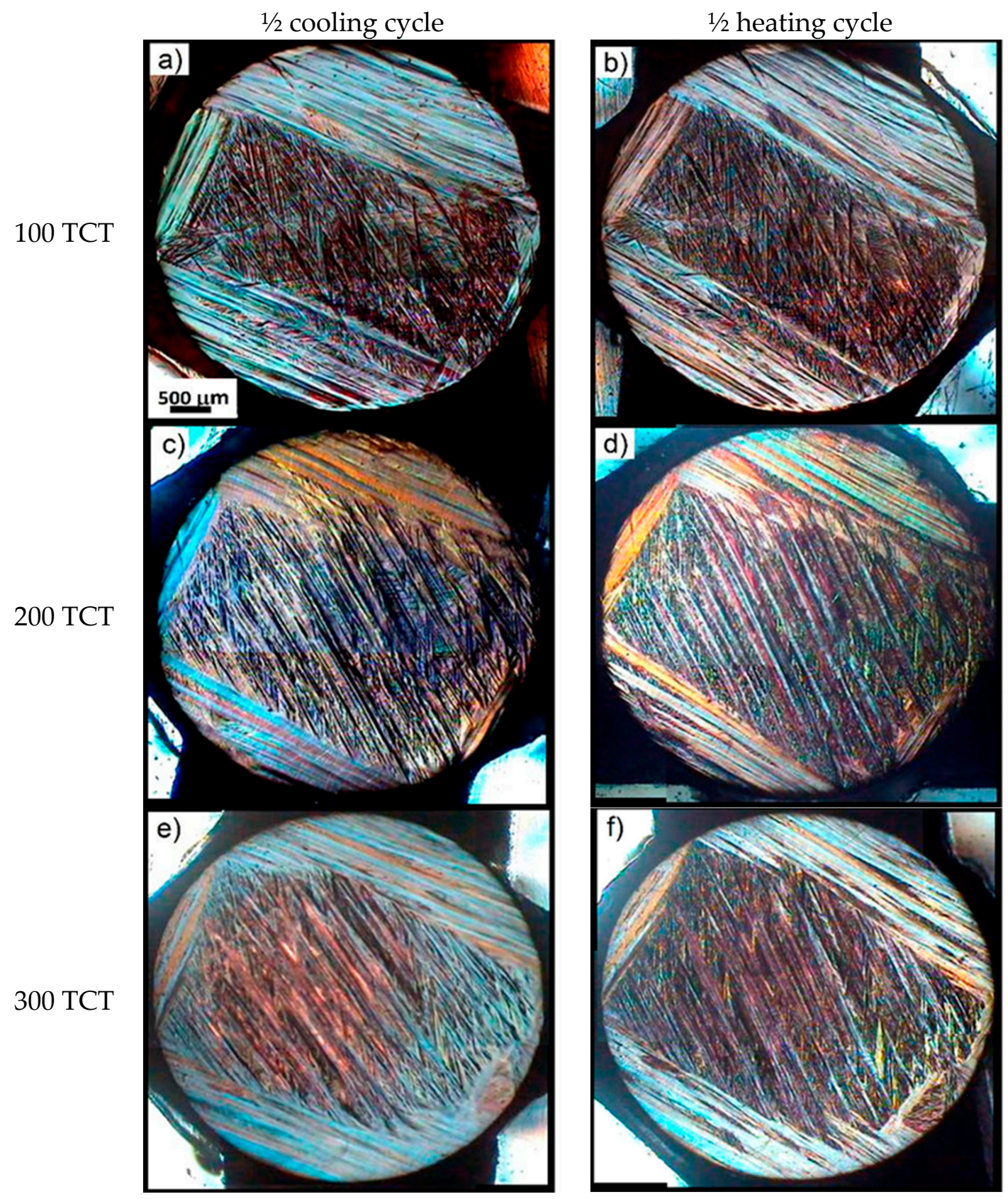

Figure 12. Microstructure of $\mathrm{Cu}-13.7 \% \mathrm{Al}-4.2 \% \mathrm{Ni}$ alloy after (a,b) 100; (c,d) 200; and (e,f) $300 \mathrm{TCTs}$ under the loading of $0.11 \mathrm{MPa}$, finished with the $(\mathbf{a}, \mathbf{c}, \mathbf{e}) 1 / 2$ cooling cycle and $(\mathbf{b}, \mathbf{d}, \mathbf{f}) 1 / 2$ heating cycle. 

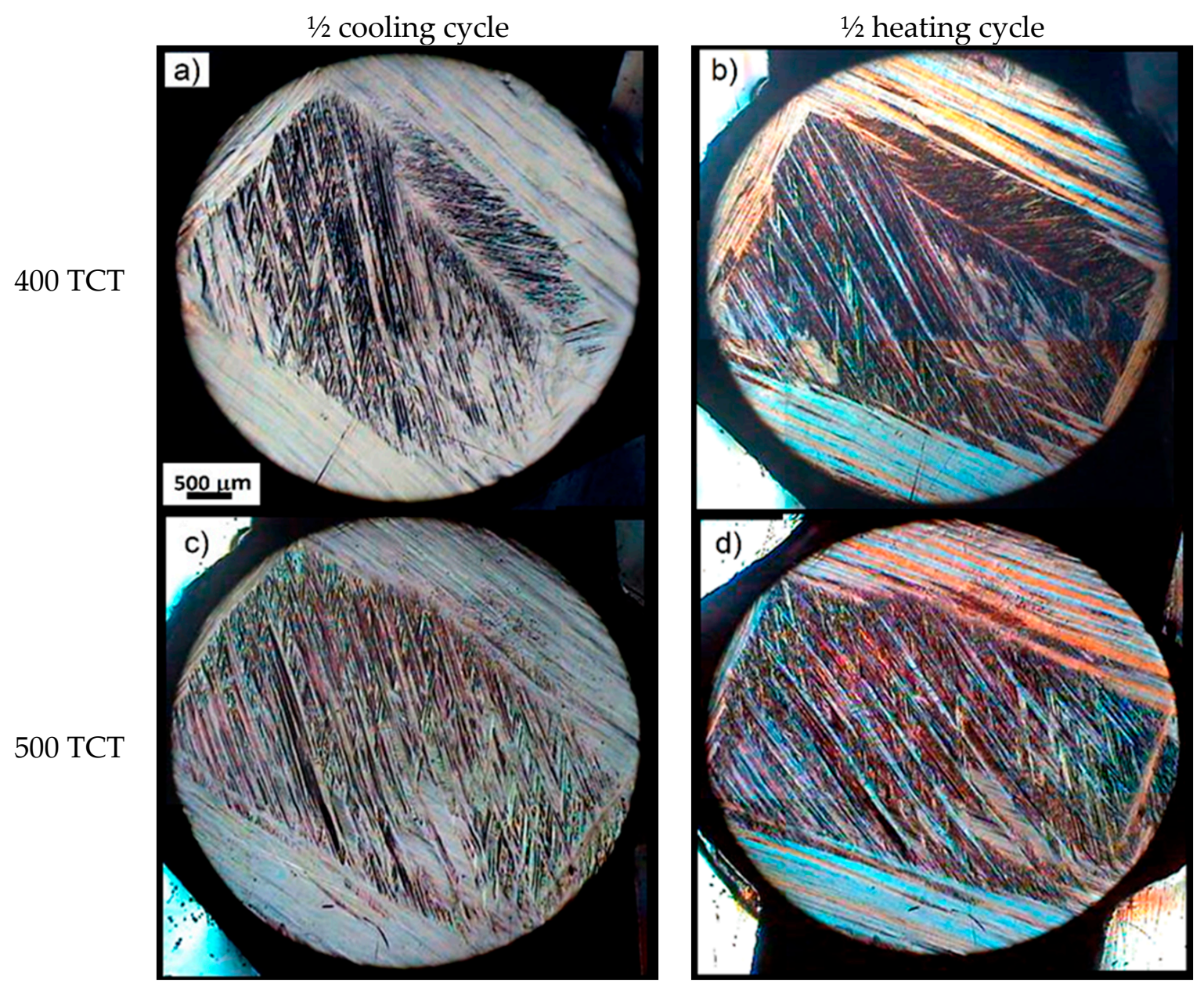

Figure 13. Microstructure of $\mathrm{Cu}-13.7 \% \mathrm{Al}-4.2 \% \mathrm{Ni}$ alloy after (a,b) 400 and (c,d) 500 TCTs under the loading of $0.11 \mathrm{MPa}$, finished with the $(\mathbf{a}, \mathbf{c}) 1 / 2$ cooling cycle and $(\mathbf{b}, \mathbf{d}) 1 / 2$ heating cycle.

After TCTs under the load of $0.11 \mathrm{MPa}$, two martensitic blocks of the peripheral region were eliminated (Figure 12a-f). With the accumulation of 400 and 500 cycles (Figure 13a-d), the martensitic lamellae were not as distinct as before, but it was possible to examine microscopic characteristics of fine needles of this $\beta^{\prime}{ }_{1}$ martensitic phase as estimated by XRD (Figure 9) [1,3].

The microstructure of $\mathrm{Cu}-13.7 \% \mathrm{Al}-4.2 \% \mathrm{Ni}$ alloy after TCTs under the load of $0.26 \mathrm{MPa}$ is shown in Figures 14 and 15. The accumulation of structural imperfections during 100 and 200 cycles promoted the development of deep sliding lines, superimposed on the specific martensitic relief (Figure 14a,c). These lines originated from the multiple RMTs induced by TCTs $[3,8,18-22]$. On heating, the superficial lines became microscopically visible due to the relief of tension (Figure 14b,d). In the peripheral part a spear-shaped needle feature, martensite $\gamma_{1}^{\prime}$ (highlighted in Figure 14b) was presented prominently in the XRD pattern of Figure 10b. With the accumulation of 300 thermal cycles, the reorientation of the martensite lamellae could be noticed (Figure 14e,f). The microstructure of the alloy after TCTs of 400 and 500 cycles was practically stable, with the completely oriented martensitic lamellae in the central region (Figure 15a-d). 

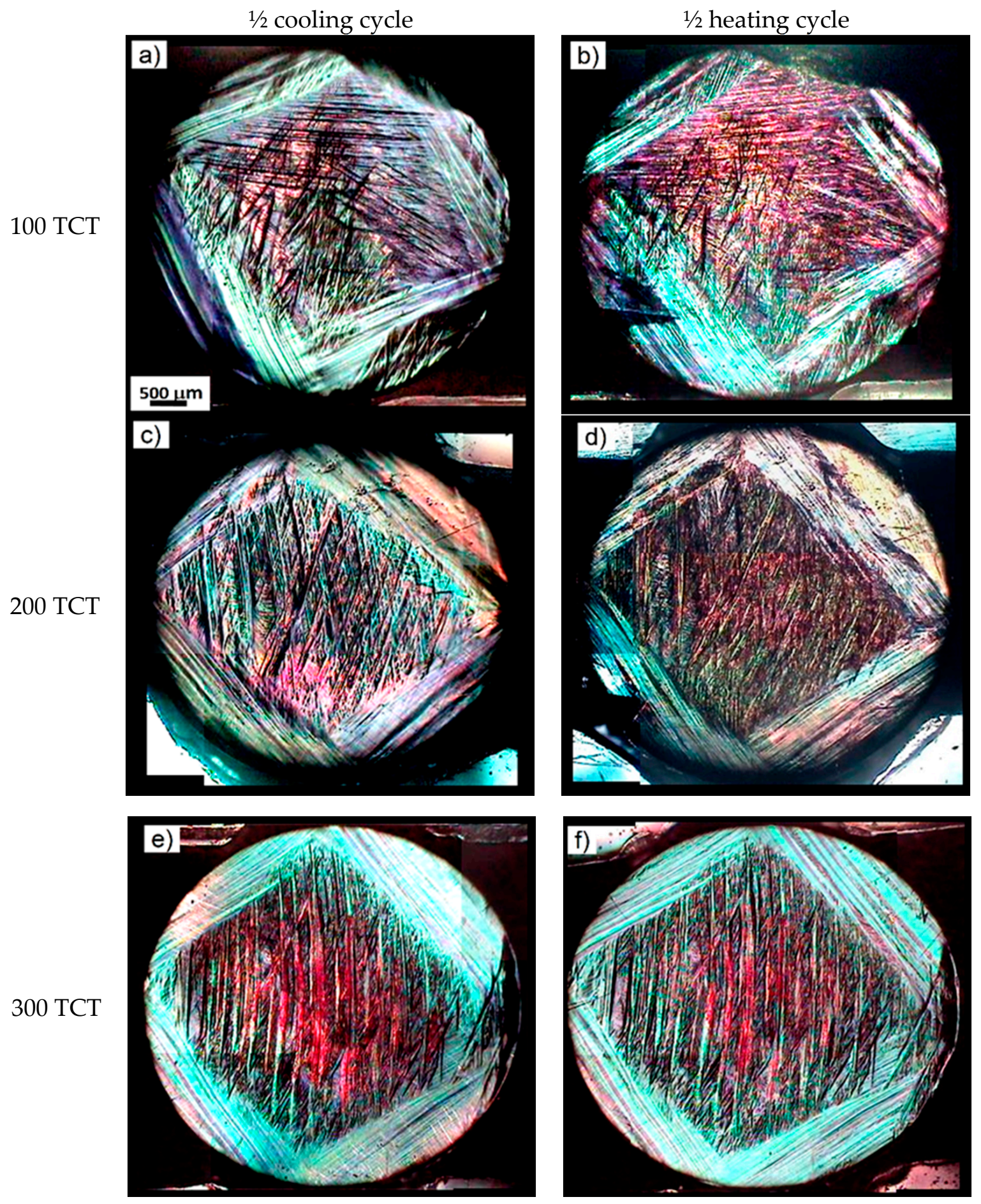

Figure 14. Microstructure of Cu-13.7\% Al-4.2\% Ni alloy after (a,b) 100; (c,d) 200; and (e,f) 300 TCTs under the loading of $0.26 \mathrm{MPa}$, finished with the $(\mathbf{a}, \mathbf{c}, \mathbf{e}) 1 / 2$ cooling cycle and $(\mathbf{b}, \mathbf{d}, \mathbf{f}) 1 / 2$ heating cycle. 


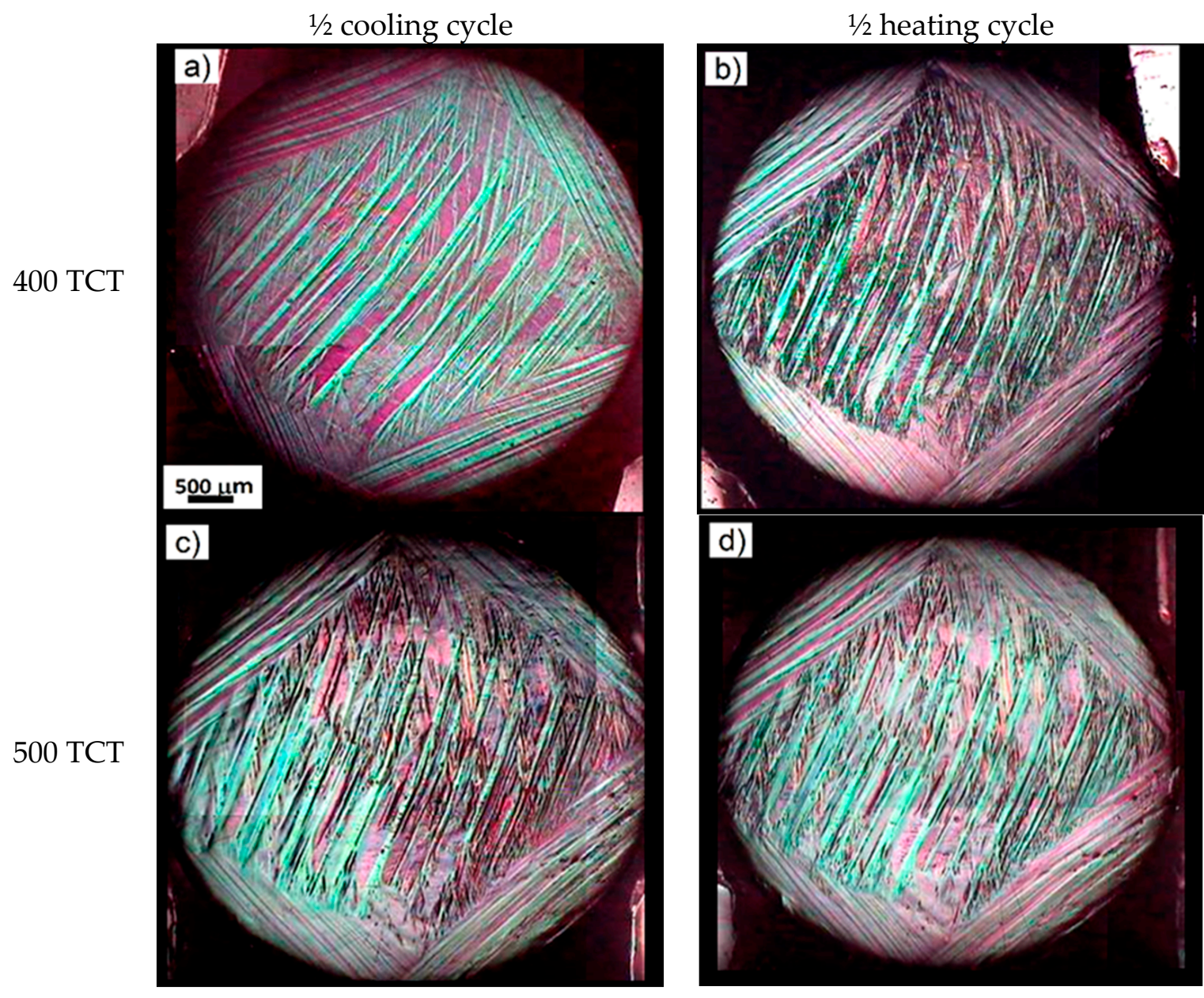

Figure 15. Microstructure of $\mathrm{Cu}-13.7 \% \mathrm{Al}-4.2 \%$ Ni alloy after (a,b) 400 and (c,d) 500 TCTs under the loading of $0.26 \mathrm{MPa}$, finished with the $(\mathbf{a}, \mathbf{c}) 1 / 2$ cooling cycle and $(\mathbf{b}, \mathbf{d}) 1 / 2$ heating cycle.

The morphological aspect of $\mathrm{Cu}-13.7 \% \mathrm{Al}-4.2 \% \mathrm{Ni}$ alloy after TCT under the load of $0.53 \mathrm{MPa}$ is shown in Figures 16 and 17. With the accumulation of thermal cycles, the martensitic relief was less pronounced, probably due to the coherency between the martensitic $\beta^{\prime}{ }_{1}$ and R-phases as noted in the diffractograms of Figure 11. With the accumulation of 300, 400, and 500 cycles, the martensitic relief changed; thus, differently oriented lamellae could be distinguished within the initial martensitic blocks (Figure 16e,f and Figure 17a,d). After TCTs, the individual blocks of the martensitic lamellae with different orientations were observed throughout the sample's cross-sectional area. It is noted that the sliding lines caused by the RMT overlapped in certain regions, where the accumulation of structural defects probably occurs during TCT tests. Nevertheless, it can be said that the structural orientation was the result of the training under the applied load. 


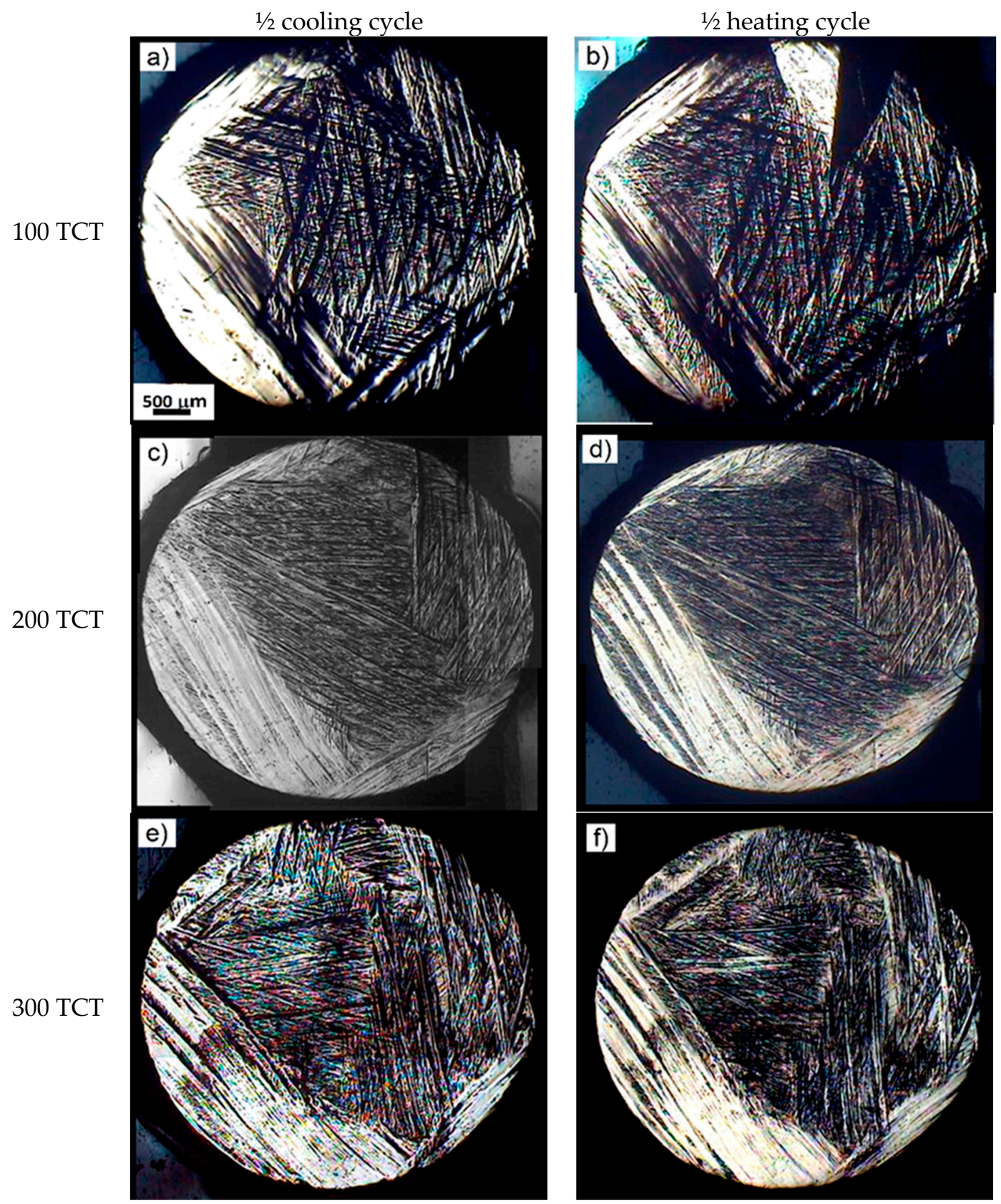

Figure 16. Microstructure of Cu-13.7\% Al-4.2\% Ni alloy after (a,b) 100; (c,d) 200; and (e,f) 300 TCTs under the loading of $0.53 \mathrm{MPa}$, finished with the $(\mathbf{a}, \mathbf{c}, \mathbf{e}) 1 / 2$ cooling cycle and $(\mathbf{b}, \mathbf{d}, \mathbf{f}) 1 / 2$ heating cycle. 

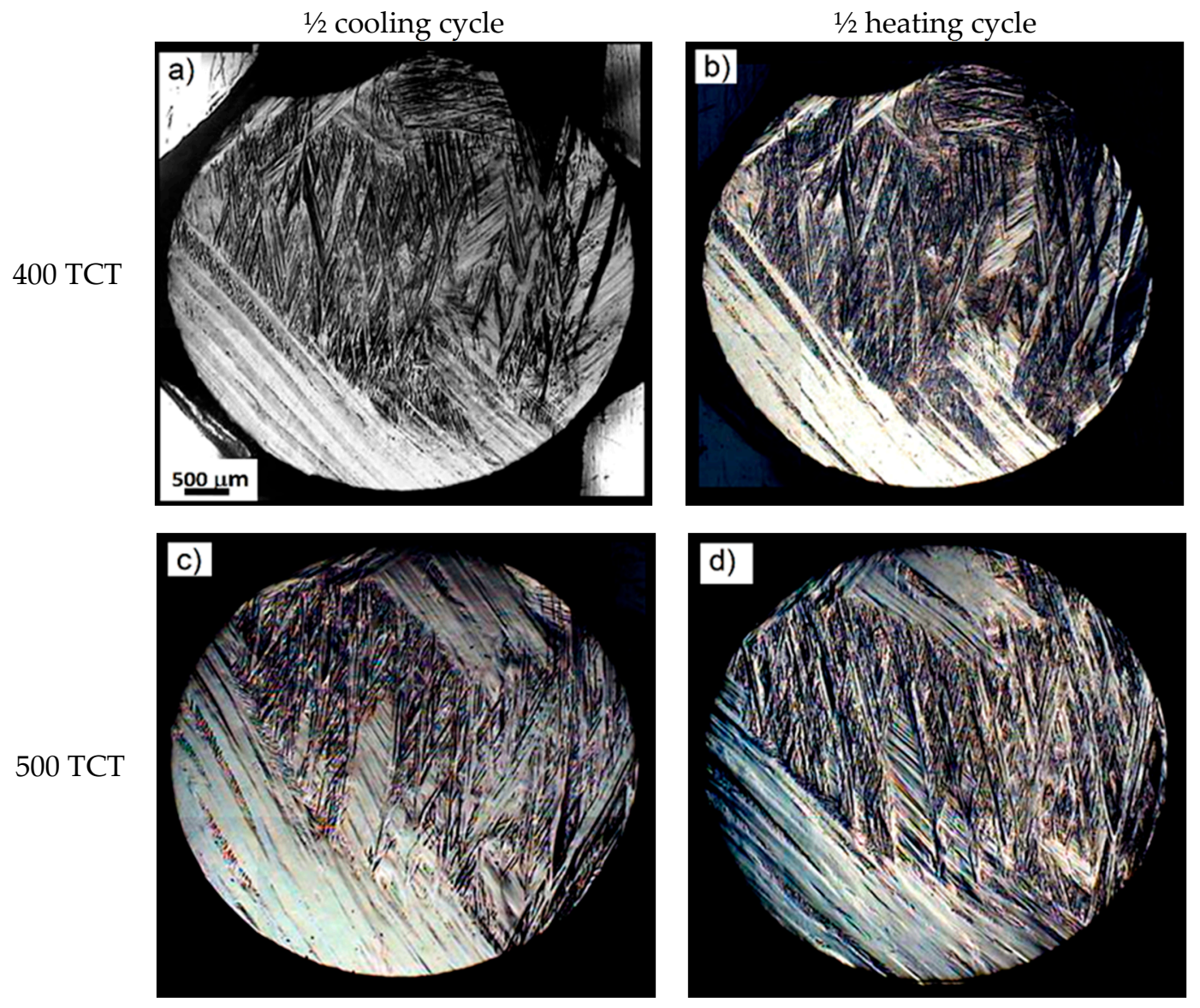

Figure 17. Microstructure of $\mathrm{Cu}-13.7 \% \mathrm{Al}-4.2 \% \mathrm{Ni}$ alloy after $(\mathbf{a}, \mathbf{b}) 400$ and (c,d) 500 TCTs under the loading of $0.53 \mathrm{MPa}$, finished with the $(\mathbf{a}, \mathbf{c}) 1 / 2$ cooling cycle and $(\mathbf{b}, \mathbf{d}) 1 / 2$ heating cycle.

\subsection{Vickers Microhardness after TCT under Loads}

The average values of Vickers microhardness as a function of the number of thermal cycles under the loads of $0.11,0.26$, and $0.53 \mathrm{MPa}$ applied to the monocrystalline $\mathrm{Cu}-13.7 \% \mathrm{Al}-4.2 \% \mathrm{Ni}$ alloy are shown in Figure 18. Determined as $303 \pm 7.8 \mathrm{kgf} / \mathrm{mm}^{2}$ in the initial state, microhardness tended to decrease after TCTs under the loads of 0.11 and $0.53 \mathrm{MPa}$, going down to $241.8 \pm 8.1 \mathrm{kgf} / \mathrm{mm}^{2}$ and $268.7 \pm 6 \mathrm{kgf} / \mathrm{mm}^{2}$, respectively, after 500 TCTs. However, after TCTs under the load of $0.26 \mathrm{MPa}$, microhardness displayed a stability plateau up to 300 thermal cycles. With the higher number of cycles, the microhardness increased from $295.3 \pm 7.9 \mathrm{kgf} / \mathrm{mm}^{2}$, after 300 cycles, to $341.9 \pm 14.5 \mathrm{kgf}$ $/ \mathrm{mm}^{2}$, after 500 thermal cycles, which could be typical for the more strained condition of any alloy with a stable structure due to the accumulation of imperfections that can hinder the development of the transformation. But, the apparent increase in microhardness can be associated with the recovery during unloading of the reversible strain accumulated by the induced martensitic transformation [1-3]. 


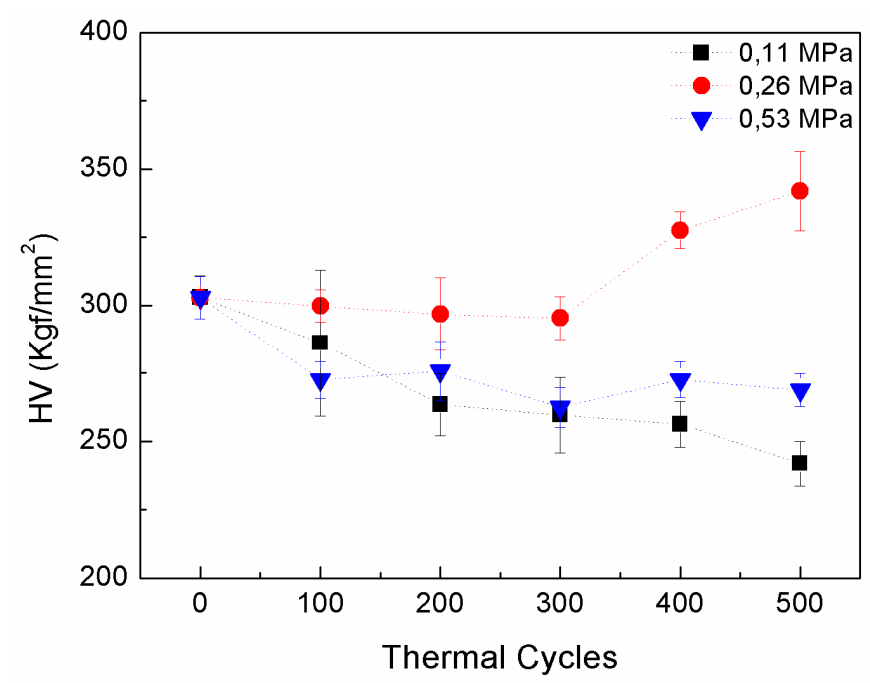

Figure 18. Vickers microhardness as function of the number of thermal cycles under loadings of 0.11 , 0.26 , and $0.53 \mathrm{MPa}$ applied to the monocrystalline $\mathrm{Cu}-13.7 \% \mathrm{Al}-4.2 \% \mathrm{Ni}$ alloy.

\section{Discussion}

The investigated alloy demonstrated complex phase transformation involving coherent phases sensitive to experimental conditions. One of the key proofs of the coherence among the phases in the alloy structure was the absence of several DSC transformation peaks, contrary to that observed in similar alloys [3,24-29]. A single RMT peak indicated the sequence of transformation $\beta_{1} \leftrightarrow R \leftrightarrow \beta^{\prime}{ }_{1}+$ $\gamma^{\prime}{ }_{1}$ in the structure of monocrystalline $\mathrm{Cu}-13.7 \% \mathrm{Al}-4,2 \% \mathrm{Ni}$ alloy.

It should be noted that after TCTs finishing with the $\frac{1}{2}$ heating cycle $\left(\mathrm{AT} \rightarrow 90^{\circ} \mathrm{C} \rightarrow \mathrm{AT}\right.$ without loading), the XRD patterns of the alloys (Figures $9 b, 10 b$ and $11 b$ ) were in good agreement with the direct RMT critical temperatures (Figures 5a, 6a and 7a). Figure 5a shows that the temperature of the direct intensive RMT $\mathrm{M}_{\mathrm{of}}$, determined after the first thermal cycle of the alloy, was above the TA, estimated by XRD analysis $\left(20 \pm 5^{\circ} \mathrm{C}\right)$; it is assumed that this is within the martensite $\gamma_{1}^{\prime}$ field (below $\mathrm{M}_{\mathrm{of}}$ ) as observed in the diffractogram of Figure $9 \mathrm{~b}$. In general, when the critical temperature $\mathrm{M}_{\mathrm{of}}$ decreased approaching AT, a greater participation of the martensite $\beta^{\prime}{ }_{1}$ and less participation of the others phases $\left(\gamma^{\prime}{ }_{1}, \beta^{\prime}{ }_{1} \mid \mathrm{R}\right.$ and $\left.\mathrm{R}\right)$ was observed in the diffractograms of Figures $9 \mathrm{~b}, 10 \mathrm{~b}$ and $11 \mathrm{~b}$.

It is noted that during all TCTs (Figures $5 b, 6 b$ and $7 b$ ), the XRD procedure for temperature $\left(20 \pm 5{ }^{\circ} \mathrm{C}\right)$ went beyond the reverse RMT temperatures even with the accumulation of TCTs, and the critical temperature $A_{f}$ was very far from TA. So, the participation of the high-temperature phase $\beta_{1}$ (mainly in the diffractograms after TCTs under the load of $0.26 \mathrm{MPa}$ (Figure 10) was assumed to be a load response that promoted reverse RMT: $\gamma^{\prime}{ }_{1}+\beta^{\prime}{ }_{1} \rightarrow \mathrm{R} \rightarrow \beta_{1}$, only partially. These results are in agreement with our previous work [18-22], where the same TCTs of a $\mathrm{Cu}-\mathrm{Al}-\mathrm{Ni}$ alloy with comparable composition were performed; however, in TCTs without the applied load, it was not noticed.

During thermal cycling under load, two thermodynamic factors had a complex effect on the implementation of reversible martensitic transformations. Firstly, the load induced reversible MTs of the $\mathrm{M} \rightarrow \mathrm{A}_{\text {def }}$ type, when heated from the martensitic phase temperature, or $\mathrm{A} \rightarrow \mathrm{M}_{\text {def }}$, when cooled from the austenitic phase temperature, thus orienting the structure in a certain way [1-3,32]. The fact of the possible reversible martensitic transformation of M- into A-phase under load, as predicted by Vasilevsky in 1971 [32], was experimentally proven in the studies on TiNi- [33-37] and $\mathrm{Cu}-\mathrm{Al}-\mathrm{Ni}$ [38]-based alloys with RMT.

Secondly, the load induced deformation that can be reversible (SME) or irreversible (inelastic deformation) in the alloys with RMT [2,3]. Reversible deformation depends on the load and it increases to a certain value (4-8\%) initially but later on decreases. In this case, the temperature ranges for the realization of RMT and SMA expanded drastically as would be studied for a TiNi alloy [33-37]. 
According to the Clausius-Clapeyron equation, the applied external stress resulted in an increase in the critical temperatures of RMT [3,39]. On the other hand, the directed action of the load promoted some orientation of the structure and facilitated the transformation of martensitic lamellae according to certain variants $[3,5]$.

As early as the 1980s in the works of Antipov et al. [40], the behavior of TiNi alloys with SME subjected to TCTs under different loads of flexural strain was analyzed. It was discovered that on heating during TCT, the return angle (determines the degree of shape restoration) decreased intensively in the first cycles and stabilized an increase in the number of thermal cycles, revealing the stabilization of the structure accompanied by a martensite reorientation and hardening. It was found that under optimized stresses, the return angle stabilization and stability of the structure develops with fewer cycles, while under low and/or excessive applied stresses, angle stabilization is delayed or even noticeable.

Comparison of the results of Antipov et al. [40] with the results of this work for the Cu-Al-Ni SMAs reveals a very similar tendency. With TCTs under the lowest applied load (0.11 MPa), structural stability with reorientation and hardening was not achieved even after TCT of 500 cycles, although critical temperatures and hysteresis showed fewer changes during cyclic tests as observed in Figures 5-8.

During TCTs under a higher applied load (0.26 MPa), RMT-induced processes of reorientation, hardening, and stabilization of the structure occurred more intensively, resulting in critical intervals reduction, microhardness increasing, and stabilization, from 300 thermal cycles. Such a conclusion was based on microhardness behavior, critical temperatures, hysteresis, and structural changes as observed in Figures 6, 8 and 18.

With the highest applied load (0.53 MPa), the reorientation and hardening processes could be expected to be faster; however, the excessive load acts both to facilitate the reorientation and to make the shape restoration difficult. As a result, the entire volume of alloy does not participate in the RMT in the limited temperature range adopted in the tests. In this process, the accumulation was more significant which slows down all the RMT reactions, increasing the critical intervals and revealing the intermediate structural states at the ambient temperature (TA) as observed in Figures 7 and 8.

Nevertheless, the changes in the main RMT parameters of monocrystalline $\mathrm{Cu}-13.7 \% \mathrm{Al}-4.2 \%$ Ni alloy after TCT under all applied loads (after "training" under loads) were not very significant, especially after complete RMT cycles which indicates good resistance of the alloy investigated to irreversible structure changes.

\section{Conclusions}

1. The monocrystalline $\mathrm{Cu}-13.7 \% \mathrm{Al}-4.2 \% \mathrm{Ni}$ alloy represents complex mixed transformation, revealing the RMT sequence $\beta_{1} \leftrightarrow \mathrm{R} \leftrightarrow \beta^{\prime}{ }_{1}+\gamma^{\prime}{ }_{1}$, where the present phases are coherent with each other and are very sensitive to structural changes.

2. Alterations in the alloy structure by finishing the $1 / 2$ cycle heating treatment $\left(\mathrm{TA} \rightarrow 90{ }^{\circ} \mathrm{C} \rightarrow \mathrm{TA}\right)$ show good consistency with the critical temperatures of direct RMT. The martensite $\gamma^{\prime}{ }_{1}$ field lies below the end of the intensive direct RMT (below $\mathrm{M}_{\mathrm{Of}}$ ). Above this temperature, a greater participation of martensite $\beta^{\prime}{ }_{1}$ is observed, coherent to phase $\mathrm{R}$.

3. The participation of the high-temperature phase $\beta_{1}$ in the alloy structure, mainly after TCTs under the load of $0.26 \mathrm{MPa}$, appears as a response of the load applied during the treatment which promotes partially the reverse $\mathrm{RMT}{\gamma^{\prime}}_{1}+\beta^{\prime}{ }_{1} \rightarrow \mathrm{R} \rightarrow \beta_{1}$.

4. During TCTs performed under optimized load (0.26 MPa), where the RMT range was not changed, the reorientation, hardening, and stabilization of the structure during RMT occur more intensively, resulting in a reduction of critical intervals, increasing and stabilizing of the microhardness, from 300 thermal cycles.

5. The changes in the main RMT parameters of monocrystalline $\mathrm{Cu}-13.7 \% \mathrm{Al}-4.2 \% \mathrm{Ni}$ alloy during TCT under load are not very significant, especially after complete RMT cycles, which indicate good resistance of the alloy investigated to irreversible changes, making its practical use feasible. 
Author Contributions: L.A.M.: conceptualization, project administration, creation of the special device for heat cycling, analyses of all results, original manuscript preparation; E.C.P.: investigation, the heat cycling tests performing, structure and DSC analyses, original figures preparation, discussion; S.A.P.: support and manufacture of the investigated alloy; C.Y.S.: DSC performing and DSC analysis, N.A.P.: discussion, translation into English and article edition, provision of referenced papers, including links and DOI. All authors have read and agreed to the published version of the manuscript.

Funding: The researchers are grateful for the research support granted by FAPERJ, CAPES, and CNPq; N.A.P. thanks the support of state assignment No. 075-00947-20-00.

Acknowledgments: The researchers are grateful for the research support granted by Luciana Lezira Pereira de Almeida technique of LAMAV/CCT/UENF for the performance of X-ray diffraction analysis.

Conflicts of Interest: The authors declare no conflict of interest. The funders had no role in the design of the study; in the collection, analyses, or interpretation of data; in the writing of the manuscript, or in the decision to publish the results.

\section{References}

1. Kurdyumov, G.V.; Khandros, L.G. On the thermoelastic equilibrium on martensitic transformations. Dokl. Akad. Nauk SSSR 1949, 66, 211-214. Available online: http://archive.ujp.bitp.kiev.ua/files/journals/53/si/ 53SI20p.pdf (accessed on 25 January 2020).

2. Perkins, J. Shape memory effects in alloys. In Proceedings of the International Symposium on Shape Memory Effects and Applications, Toronto, ON, Canada, 19-20 May 1975; Available online: https://www.springer. com/gp/book/9781468422139 (accessed on 25 January 2020).

3. Otsuka, K.; Wayman, C.M. (Eds.) Shape Memory Materials; Cambridge University Press: Cambridge, UK, 1999; Available online: https://ru.scribd.com/document/368059783/K-Otsuka-C-M-Wayman-Shape-MemoryMaterials-Cambridge-University-Press-1998 (accessed on 25 January 2020).

4. Duerig, T.W.; Pelton, A.; Stöckel, D. An overview of nitinol medical applications. Mater. Sci. Eng. A 1999, 273, 149-160. [CrossRef]

5. Otsuka, K.; Ren, X. Physical metallurgy of Ti-Ni-based shape memory alloys. Prog. Mater. Sci. 2005, 50, 511-678. [CrossRef]

6. SMST-2017: Nitinol and Beyond. In Proceedings of the International Conference on Shape Memory and Superelastic Technologies (SMST 2017), San Diego, CA, USA, 15-19 May 2017; Volume 1, p. 230. Available online: https:/www.asminternational.org/web/smst/events/proceedings/-/journal_content/56/ 10192/37425484/PUBLICATION (accessed on 25 January 2020).

7. Font, J.; Cesari, E.; Muntasell, J.; Pons, J. Thermomechanical cycling in Cu-Al-Ni-based melt-spun shape-memory ribbons. Mater. Sci. Eng. A 2003, 354, 207-211. [CrossRef]

8. Tadaki, T. Cu-based shape memory alloys. In Shape Memory Materials; Otsuka, K., Wayman, C.M., Eds.; Cambridge University Press: Cambridge, UK, 1999; pp. 97-116.

9. Martynov, V.; Bokate, M.D.; Johnson, A.D.; Grey, G.R. Superelastic and shape memory single Crystal $\mathrm{Cu}-\mathrm{Al}-\mathrm{Ni}$ : Fabrication and Applications. In Proceedings of the International Conference on Shape Memory and Superelastic Technologies, Pacific Grove, CA, USA, 7-11 May 2006; pp. 427-439. Available online: http://docplayer.net/50163627-Smst-shape-memory-and-superelastic-technologies-proceedings-ofthe-international-conference-on.html (accessed on 25 January 2020).

10. Pulnev, S.; Nikolaev, V.; Priadko, A.; Rogov, A.; Vahhi, I. Actuators and drivers based on CuAlNi shape memory single crystals. J. Mater. Eng. Perform. 2011, 20, 497-499. [CrossRef]

11. Morin, M.; Trivero, F. Influence of thermal cycling on the reversible martensitic transformation in a Cu-Al-Ni shape memory alloy. Mater. Sci. Eng. A 1995, 196, 177-181. [CrossRef]

12. Silva, R.J.C.; Matlakhova, L.A.; Pereira, E.C.; Matlakhov, A.N.; Monteiro, S.N.; Rodríguez, R.J.S. Thermal cycling treatment and structural changes in $\mathrm{Cu}-\mathrm{Al}-\mathrm{Ni}$ monocrystalline alloys. Mater. Sci. Forum Trans. Tech. Publ. 2006, 514, 692-696. [CrossRef]

13. Matlakhova, L.A.; Motta, A.C.; Matlakhov, A.N.; Pereira, E.C.; Toledo, R.; Monteiro, S.N. Estrutura de ligas monocristalinas Cu-Al-Ni após ciclagem térmica. Technol. Metall. Mater. Min. 2009, 6, 80-85.

14. Hund, F.; Fricke, R. Der Kristallbau von $\alpha$-BiF3. Z. Anorg. Chem. 1949, 258, 198-204. [CrossRef]

15. Vol, A.E. The Structure and Properties of Binary Systems; Fizmatgiz: Moscow, Russia, 1959; Volume 1, p. 755.

16. Bown, M.G. The structure of rhombohedral T (NiCuAl). Acta Crystallogr. 1956, 9, 70-74. [CrossRef] 
17. Shishkovsky, I.; Yadroitsev, I.; Morozov, Y. Laser-assisted synthesis in Cu-Al-Ni system and some of its properties. J. Alloys Compd. 2016, 658, 875-879. [CrossRef]

18. Matlakhova, L.A.; Pereira, E.C.; Matlakhov, A.N.; Monteiro, S.N. Structure and properties of a monocrystalline $\mathrm{Cu}-\mathrm{Al}-\mathrm{Ni}$ alloy submitted to thermal cycling under load. In Shape Memory Alloys: Manufacture, Properties and Applications; Nova Publishers: Hauppauge, NY, USA, 2010; ISBN 978-1-60741-789-7. Available online: http://www.novapublishers.org/catalog/product_info.php?products_id=20903 (accessed on 25 January 2020).

19. Pereira, E.C.; Matlakhova, L.A.; Matlakhov, A.N.; Monteiro, S.N.; Rodriguez, R.S. Effect of applied load on the characteristics of reversible martensitic transformation during thermal cycling treatment of a monocrystalline Cu-13.5Al-4Ni alloy. Mater. Sci. Res. J. 2010, 4, 15-36. Available online: https://www.researchgate. net/publication/286317945_Effect_of_applied_load_on_the_characteristics_of_reversible_martensitic_ transformation_during_thermal_cycling_treatment_of_a_monocrystalline_Cu-13.5Al-4Ni_alloy (accessed on 25 January 2020).

20. Matlakhova, L.A.; Pereira, E.C.; Matlakhov, A.N.; Monteiro, S.N.; Rodriguez, R.S. Stress assisted thermal cycling treatment of a monocrystalline Cu-Al-Ni alloy. Mater. Sci. Res. J. 2011, 5, 31-50.

21. Pereira, E.C.; Matlakhova, L.A.; Matlakhov, A.N.; Shigue, C.Y.; Monteiro, S.N. Physical and Structural Characterization of a Monocrystalline Cu-13.7Al-4.2Ni Alloy Subjected to Thermal Cycling Treatments. Metall. Mater. Trans. A 2014, 45, 1866-1875. [CrossRef]

22. Pereira, E.C.; Matlakhova, L.A.; Matlakhov, A.N.; Araújo, C.J.; Shigue, C.Y.; Monteiro, S.N. Reversible martensite transformations in thermal cycled polycrystalline $\mathrm{Cu}-13.7 \% \mathrm{Al}-4.0 \% \mathrm{Ni}$ alloy. J. Alloys Compd. 2016, 688, 436-446. [CrossRef]

23. Pul'nev, S.A.; Nikolaev, V.I.; Malygin, G.A.; Kuz'min, S.L.; Shpeizman, V.V.; Nikanorov, S.P. Generation and relaxation of reactive stresses in Cu-Al-Ni shape-memory alloy. Tech. Phys. 2006, 51, 1004-1007. [CrossRef]

24. Recarte, V.; Pérez-Sáez, R.B.; Bocanegra, E.H.; Nó, M.L.; San Juan, J. Dependence of the martensitic transformation characteristics on concentration in $\mathrm{Cu}-\mathrm{Al}-\mathrm{Ni}$ shape memory alloys. Mater. Sci. Eng. A 1999, 273, 380-384. [CrossRef]

25. Recarte, V.; Pérez-Sáez, R.B.; Nó, M.L.; San Juan, J. Evolution of martensitic transformation in Cu-Al-Ni shape memory alloys during low-temperature aging. J. Mater. Res. 1999, 14, 2806-2813. [CrossRef]

26. Recarte, V.; Pérez-Sáez, R.B.; Nó, M.L.; San Juan, J. Ordering kinetics in Cu-Al-Ni shape memory alloys. J. Appl. Phys. 1999, 86, 5467-5473. [CrossRef]

27. Recarte, V.; Pérez-Sáez, R.B.; San Juan, J.; Bocanegra, E.H.; Nó, M.L. Influence of Al and Ni concentration on the martensitic transformation in Cu-Al-Ni shape-memory alloys. Metall. Mater. Trans. A 2002, 33, 2581-2591. [CrossRef]

28. Ibarra, A.; Caillard, D.; San Juan, J.; Nó, M.L. Martensite nucleation on dislocations in Cu-Al-Ni shape memory alloys. Appl. Phys. Lett. 2007, 90, 101-107. [CrossRef]

29. Ibarra, A.; San Juan, J.; Bocanegra, E.H.; Nó, M.L. Evolution of microstructure and thermomechanical properties during superelastic compression cycling in $\mathrm{Cu}-\mathrm{Al}-\mathrm{Ni}$ single crystals. Acta Mater. 2007, 55, 4789-4798. [CrossRef]

30. Nishiyama, Z. Martensitic Transformations; Fine, M.E., Meshii, M., Wayman, C.M., Eds.; Academic Press: San Francisco, NY, USA, 1978; p. 480.

31. Swann, P.R.; Warlimont, H. The electron-metallography and crystallography of copper-aluminum martensites. Acta Metall. 1963, 11, 511-527. [CrossRef]

32. Wasilewski, R.J. The effects of applied stress on the martensitic transformation in TiNi. Metall. Mater. Trans. 1971, 2, 2973-2981. [CrossRef]

33. Kovneristy, Y.K.; Fedotov, S.G.; Matlakhova, L.A. Effect of deformation on phase transformations and modulus of elongation in titanium nickelide-Based alloy. In Proceedings of the 5th International Conference on Titanium, Munich, Germany, 10-14 September 1984; Volume 3, pp. 1673-1681.

34. Kovneristy, Y.K.; Fedotov, S.G.; Matlakhova, L.A.; Oleynikova, S.V. Shape memory and shape reversibility effects in a TiNi alloy as a function of deformation. Fiz. Met. Metallogr. (USSR) 1986, 62, 124-129.

35. Kovneristy, Y.K.; Fedotov, S.G.; Matlakhova, L.A. The influence of plastic deformation on the structure, shape memory effect and other properties of TiNi alloy. In Proceedings of the International Symposium CN Shape Memory Alloys, Guilin, China, 6-9 September 1986; pp. 175-180.

36. Fedotov, S.G.; Kovneristy, Y.K.; Matlakhova, L.A.; Zhebynieva, N.F. Structural changes in alloy TiNi with the shape memory effect during deformation. Phys. Met. Metall. 1988, 65, 564-569. 
37. Matlakhova, L.A.; Belousov, O.K.; Palii, N.A. Elastic Modulus and structure changes in TiNi during SME and RSME. Available online: https://www.lap-publishing.com/catalog/details//store/gb/book/978-613-9-85937-5/ elastic-modulus-and-structure-changes-in-tini-during-sme-and-rsme?locale=ru (accessed on 25 January 2020).

38. Matlakhova, L.A.; Motta, A.C.; Matlakhov, A.N.; Kolmakov, A.G.; Sevostianov, M.A. Módulo de elasticidade da liga monocristalina $\mathrm{Cu}-\mathrm{Al}-\mathrm{Ni}$ deformada por compressão. In Proceedings of the 18th Brazilian Congress of Engineering and Materials Science-CBECiMat, Porto de Galinhas, Brazil, 24-28 November 2008; pp. 6463-6474. Available online: https://www.scribd.com/document/50128870/18Cbecimat (accessed on 25 January 2020).

39. Pérez-Landazábal, J.I.; Recarte, V.; Pérez-Sáez, R.B.; Nó, M.L.; Campo, J.; San Juan, J. Determination of the next-nearest neighbor order in $\beta$ phase in $\mathrm{Cu}-\mathrm{Al}-\mathrm{Ni}$ shape memory alloys. Appl. Phys. Lett. 2002, 81, 1794-1796. [CrossRef]

40. Antipov, A.I.; Matlakhova, L.A.; Tolmachev, A.N.; Oleinikova, S.V.; Zebyneva, N.F. Effect of Thermomechanical Treatment on the Shape Memory Effect in TN-1 Alloys. Fiz. Khim. Obrab. Mater. 1981, 6, 67-70.

(C) 2020 by the authors. Licensee MDPI, Basel, Switzerland. This article is an open access article distributed under the terms and conditions of the Creative Commons Attribution (CC BY) license (http://creativecommons.org/licenses/by/4.0/). 